\title{
Incremental Digital Twin Conceptualisations Targeting Data-Driven Circular Construction
}

\author{
Pedro Mêda ${ }^{1, *(\mathbb{D})}$, Diego Calvetti ${ }^{1}$ (D) Eilif Hjelseth $^{2}$ and Hipólito Sousa $^{1}$ (D) \\ 1 CONSTRUCT/GEQUALTEC, Construction Institute, Faculty of Engineering, Porto University, \\ 4200-465 Porto, Portugal; diegocalvetti@fe.up.pt (D.C.); hipolito@fe.up.pt (H.S.) \\ 2 Department of Civil and Environmental Engineering, Norwegian University of Science and Technology, \\ 7491 Trondheim, Norway; eilif.hjelseth@ntnu.no \\ * Correspondence: pmeda@fe.up.pt
}

check for

updates

Citation: Mêda, P.; Calvetti, D.; Hjelseth, E.; Sousa, H. Incremental Digital Twin Conceptualisations Targeting Data-Driven Circular Construction. Buildings 2021, 11, 554. https://doi.org/10.3390/ buildings 11110554

Academic Editors: David J. Edwards, Clinton Aigbavboa,

Obuks Ejohwomu and Chris Roberts

Received: 27 September 2021

Accepted: 14 November 2021

Published: 18 November 2021

Publisher's Note: MDPI stays neutral with regard to jurisdictional claims in published maps and institutional affiliations.

Copyright: (c) 2021 by the authors. Licensee MDPI, Basel, Switzerland. This article is an open access article distributed under the terms and conditions of the Creative Commons Attribution (CC BY) license (https:// creativecommons.org/licenses/by/ $4.0 /)$.

\begin{abstract}
The construction industry faces multiple challenges, where transition to circular production is key. Digitalisation is a strategy to increase the sector's productivity, competitiveness, and efficiency. However, digitalisation also impacts environmental goals, such as those concerning more eco-friendly solutions, energy efficiency, products recycling, and sustainability certifications. These strategies rely on data, understood as digital, interoperable, incremental and traceable. Data related concepts, such as digital data templates (DDT) and digital building logbooks (DBL), contribute to "good data". Despite some research focused on each one, little importance has yet been given to their combination. Relevant relationships and overlaps exist, as they partially share the exact same data through the built environment life cycle. This research aims to provide improved understanding on the role of these concepts and their contribution to a more circular industry. The review develops conceptualisations where DDT and DBL are complementary and framed within an incremental digital twin construction (DTC). Misconceptions or confrontations between these three solutions can therefore stand down, for the benefit of a data-driven priority. To increase understanding and reduce misconceptions, our study developed the "Digital data-driven concept" (D3c). This concept contribution is the ability to structure, store, and trace data, opening way to streamlined digital transformation impacting circular built environment concerns.
\end{abstract}

Keywords: digitalisation; Construction 4.0; data templates; building logbook; traceability; concepts overlap

\section{Introduction}

The construction industry (CI) has one of the most linear value chains among all economic activities. The adoption of more circular practices is an imperative for the architecture, engineering, construction, and owner operator (AECOO) sector. Sustainability megatrends in this field point to the reuse of construction products, waste reduction, and more resource-efficient processes [1-4]. Increasing the energy efficiency of public and residential buildings is vital to improve the population's quality of life [3]. Knowledge and data regarding the building elements within a sensored built environment is a subject that has been standing at the border of research and discussions. However, it is a key issue that must be brought to the centre, given the relevance and added value supporting the industry's goal accomplishments. Digital twins (DT) are part of this digital transformation strategy. It is a data-focused concept and allows bi-directional data interaction between the physical built and a digital/responsive twin [5].

A circular and sustainable building environment is an envisaged outcome in many EU initiatives. The European Green Deal comprises several elements to transform the EU economy towards a more sustainable future [1]. The Renovation Wave strategy is an ambitious plan, aiming to renovate 35 million building units by 2030, to increase energy efficiency, and reduce greenhouse gas emissions by $60 \%$ [3]. Monitoring chains of products 
and services to evaluate circular economy progression and achievements is a challenging job [2]. Waste audits, which aim to identify the amounts of construction products in buildings and infrastructures, point to potential reuse scenarios or visions of constructions as material banks [4]. Improved information management and tools or technologies to better understand and capture construction products characteristics is a key requirement. Circular and sustainable construction gains new focus areas, where information circularity and traceability are critical for more efficient and sustainable practices. In brief, the construction industry's digital transformation is crucial to integrate processes and technologies aiming to overcome many challenges, identified in the previous mentioned initiatives [6].

Digital solutions are spread across the construction industry and focus on automating processes across the whole built environment's life cycle. The DT concept integrates many technologies and methodologies, such as building information modelling (BIM) [7,8]. BIM is a methodology that, among other roles, has the capability to compose the building elements targeting assets visualisation, information, and preparation for operation [6]. Several systems assist the construction process, from the design (e.g., software for structural dimensioning), through execution or construction (e.g., systems for the development and monitoring schedules), to information repositories (e.g., common data environment (CDE), databases, and information containers) that should later be used in the use phase (facility or asset management).

Digital twin aims to interconnect sensors in physical assets to cyberspace, fostering the collection, processing, and analysis of data to simulate and control the assets or built objects $[7,9,10]$. The DT concept can still be vague, but for the construction industry's purpose, it is essential to understand that its materialisation starts at project's early phases and will support increasing dimensions during the construction process. It gains shape throughout the project's execution, intercommunicating data at all times, and thus the digital twin construction (DTC) [8] terminology becomes more appropriate or specific for this sector. In addition, an incremental approach will best serve the construction process evolution and the DTC minimum abilities. According to Sacks et al. (2020), "Digital twin construction (DTC) is a new mode for managing production in construction that leverages the data streaming from a variety of site monitoring technologies and artificially intelligent functions to provide accurate status information and to proactively analyse and optimise ongoing design, planning, and production. DTC applies Building Information Modeling technology and processes, lean construction thinking, the Digital Twin Concept, and AI to formulate a datacentric mode of construction management." [8] (p. 1). To support the on-site (construction phase) management capability, a sensored construction site is needed to monitor workers, products, and equipment or machines [11]. In addition, a smart building, during the operation or use phase, runs from a DT platform powered by an Internet of Things (IoT). It is through this "Smart-Digital-Building-Twin" relation (i.e., digital twins) that the built systems are controlled and operated (e.g., energy management, assets management, indoor comfort, safety, and security) [12]. However, there cannot be a digital twin without data, understood as digital, interoperable, and traceable.

Data templates are standardised, and interoperable metadata structures are used to describe the characteristics of the construction products [13]. Data templates are meant to be information exchange enablers across the construction's life cycle. Based on that and to prevent misconceptions, data templates are addressed in this research as digital data templates (DDT), where the use of "digital" aims to highlight the alignment with the requirements set on ISO standards. Product catalogues are digital warehouses of data templates and data sheets for a specific manufacturer or crossing several ones.

The European Commission has been working on the conceptualisation of the digital building logbook (DBL).

According to the EU (2020), the digital building logbook "is a common repository for all relevant building data. It facilitates transparency, trust, informed decision-making, and information sharing within the construction sector, among building owners and occupants, financial institutions, and public authorities. A digital building logbook is a dynamic tool that allows a variety of data, 
information and documents to be recorded, accessed, enriched and organised under specific categories. It represents a record of major events and changes over a building's lifecycle, such as change of ownership, tenure or use, maintenance, refurbishment and other interventions." [14] (p. 5).

DDT and DBL overlap in data and in built environment life cycle processes. Many initiatives and projects have been approaching these topics individually, lacking holistic and common approaches focused on perceiving and working the similarities and potential benefits [15]. An improved understanding of the existing overlaps is found to be a key enabler for digital transformation strategies (data platform-based) in the AECOO sector.

Considering the different ongoing developments within the scope of Construction 4.0 and considering the initiatives to better reuse and recycle construction components or products, this work sets, as starting point, the common element to all these actions-data. Construction-related data impacts all stakeholders, throughout the entire construction life cycle. The capability to better structure and manage data, is found to be crucial for the industry.

The purpose and main aim of this work is to provide awareness to stakeholders for the relevance of data and clarity regarding the understanding and role of digital data templates, digital building logbooks, and digital twin construction as joint digital solutions. The CI must become more circular. A digital data-driven concept (D3c), powered by an incremental digital twin concept, is the solution. The conceptualisations delivered in this study seek to evidence how do these concepts and solutions overlap, and how these overlaps are found to provide a more autonomous digital twin, targeting circular decision making. If a product or element can be reused or recycled, its information can also be. Likewise, the monitoring of construction-related data, such as craft workforce data, fosters improvements in site processes. Therefore, the ability to capture, store, add, and trace all this data will not just improve the construction life cycle management but also support the built environment and its constituent parts at the end of life. This digital understanding fosters a transformation that impacts the CI performance and the built environment circularity.

\section{Method}

A scoping review was conducted to map the existing research in the area of DDT, DBL, and DTC to identify overlaps between these three subjects and focus on contributions toward sustainability and a circular economy. A series of keywords and combinations were devised and tested (see Table 1) in order to diagnose a set of actions that constitute the object of this research, namely:

- Digital twins in the construction industry (sensored sites or buildings and bi-directional data interaction).

- Digital building logbooks enabling digital twin construction.

- Digital data templates enabling digital twin construction.

- Circular construction powered by digital twin construction.

- Sustainability of building environments powered by digital twin construction.

All searches were carried out on the multidisciplinary scientific databases Scopus and Web of Science (WOS) during the second week of May 2021. When searching for the overlap of subjects, few or no studies were found. When querying the concepts, isolated results reached a large number of documents. However, they were too generic or do not specifically address the construction sector. Thus, documents were considered valid for this analysis when the combination of keywords presented returns entirely aligned with the intended research topic. Table 1 evidences the achieved search results where, without any restriction, 56 documents (validated results) were collected. 
Table 1. Keywords combination to the literature selection.

\begin{tabular}{cccc}
\hline Keywords & Scopus & WOS & Observation \\
\hline $\begin{array}{c}\text { "digital twin" and "building } \\
\text { logbook" and "data template" }\end{array}$ & 0 & 0 & No results \\
\hline "digital twin" & 3778 & 1705 & $\begin{array}{c}\text { Broad search, mostly } \\
\text { content out of context }\end{array}$ \\
\hline "digital twin construction" & 7 & 3 & Validated result \\
\hline "building logbook" & 3 & 2 & Validated result \\
\hline "buildings passport" & 5 & 0 & Validated result \\
\hline "data template" & 146 & 69 & $\begin{array}{c}\text { Broad search, mostly } \\
\text { content out of context }\end{array}$ \\
\hline "product data template" & 6 & 1 & Validated result \\
\hline "sensored construction sites" & 1 & 1 & Validated result \\
\hline "smart buildings" & 3875 & 1765 & $\begin{array}{c}\text { Broad search, mostly } \\
\text { content out of context }\end{array}$ \\
\hline "smart buildings" and "digital twin" & 23 & 4 & Validated result \\
\hline "circular construction" & 65 & 38 & $\begin{array}{c}\text { Broad search, mostly } \\
\text { content out of context }\end{array}$ \\
\hline "sustainability" and "digital twin \\
construction"
\end{tabular}

Firstly, the duplicated documents were excluded from selecting a relevant and manageable set of studies among the identified pieces of literature. As the works were recent (from 2014), chronological criteria for exclusion were not applied. In addition, all identified documents were in English, meaning that no exclusion was necessary for that reason. Nor was the geographical factor used as an exclusion criterion. Finally, the title and abstract of all documents were scrutinised to assess adherence to the topic under study. As a result, 23 documents remained.

Based on the authors' backgrounds and previous works, a series of articles and theses were pointed out as relevant references for the scope of the research. From these, most were captured by the search, but 11 documents were added. In addition, other documents were added as standards, reports, and initiatives or strategic guidelines (24 documents) that incorporate DDT, DBL, and DTC solutions or focus on circularity and sustainability within the construction industry. As mentioned, these documents have different origins and strengths, and their selection is related to detailed knowledge of the content and strategic contribution to the research outcomes. Most of the documents related to DBL come from the EU, due to the extensive use of this concept on the most recent strategies published related to digitalisation and sustainability.

The method presented in Figure 1 highlights the process of collecting all the references leading to the 58 pieces of literature selected. There are many other concepts that could be considered, as COBie, IFC, or product classification systems; however, these were found to be lateral for the goals of this study. Based on the selected literature, a review was conducted to identify any existing gaps in the knowledge. Finally, a conceptual framework integrating DDT, DBL, and DTC was developed and proposed. 


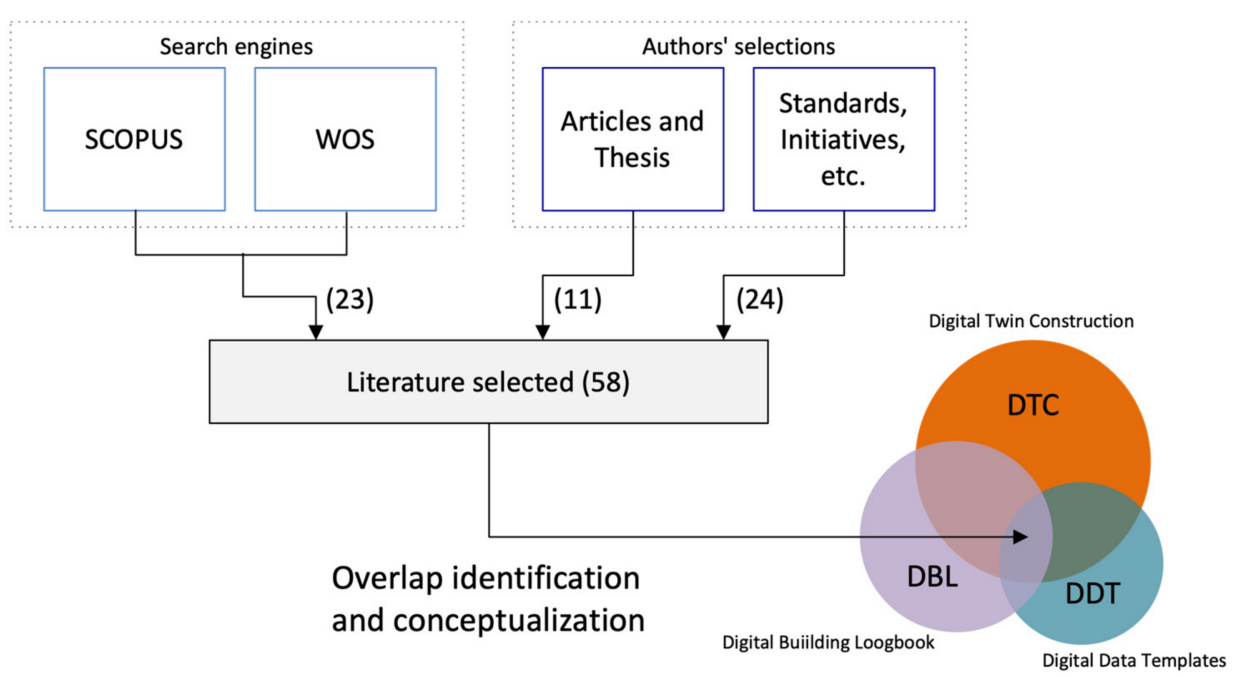

Figure 1. Scoping review focused on digital solution overlapping identification.

\section{Analysis and Results}

This section is composed of two main parts. The first part, corresponding to Section 3.1, presents and explores the review results, briefly identifying the digital solutions approached and the research's main aim. Following, the next subsections present and explore the underlying concepts, understandings, and misconceptions associated to DDT, DBL, and DTC, establishing relationships with other relevant topics and aiming to provide clarity, fostering the realization of the existing overlaps.

\subsection{Literature Review}

Figure 2 presents the keywords connection extracted from the 34 documents (23 from Scopus or WOS plus 11 articles or theses selected by the authors). The analysis was conducted using VOS viewer software and Figure 2 was formulated from it. A total of 12 items were identified into 3 clusters: cluster 1 (green dots) composed of artificial intelligence (AI), Construction 4.0, decision support, efficiency, and IFC; cluster 2 (red dots), composed of built environment, digital twin, IoT, smart building, and smart city. The building information modelling (isolated in cluster 3-blue dot) connects the other two clusters. The keywords mapping highlights how this is a new topic in the academic field. The shadow colours aim to highlight the time sluices, where light yellow represents publications dated from 2020 and light red indicates publications dated from 2019. The pie charts below, from left to right, aim to disclose the date of the publications, their origin in terms of country, and the journals where these were published.

As observed, the identified keywords are collected from publications from 2019 onwards. The topics of Construction 4.0, built environment, AI, and digital twin are now present in publications from 2020. BIM remains a fundamental subject in academic research. As part of the realization, it is necessary to understand that the information related to the objects that make up the constructions is vital to supply systems and technologies to foster improved outcomes.

Tables 2-4 present the scoping review contents, targeting the digital solutions investigated and highlighting the main aims identified. Be aware that the search may not necessarily be directly related to one of the indicated digital solutions (e.g., the search may have taken place before the methodological advent, in which case, as an example, there may be a reference to the "building logbook", nowadays referred to as "digital" building logbook). Figure 3 summarizes and provides an overview on the results from these tables. The image related to Table 4 evidences the documents. In the following subsections, the themes under analysis are detailed and discussed. 


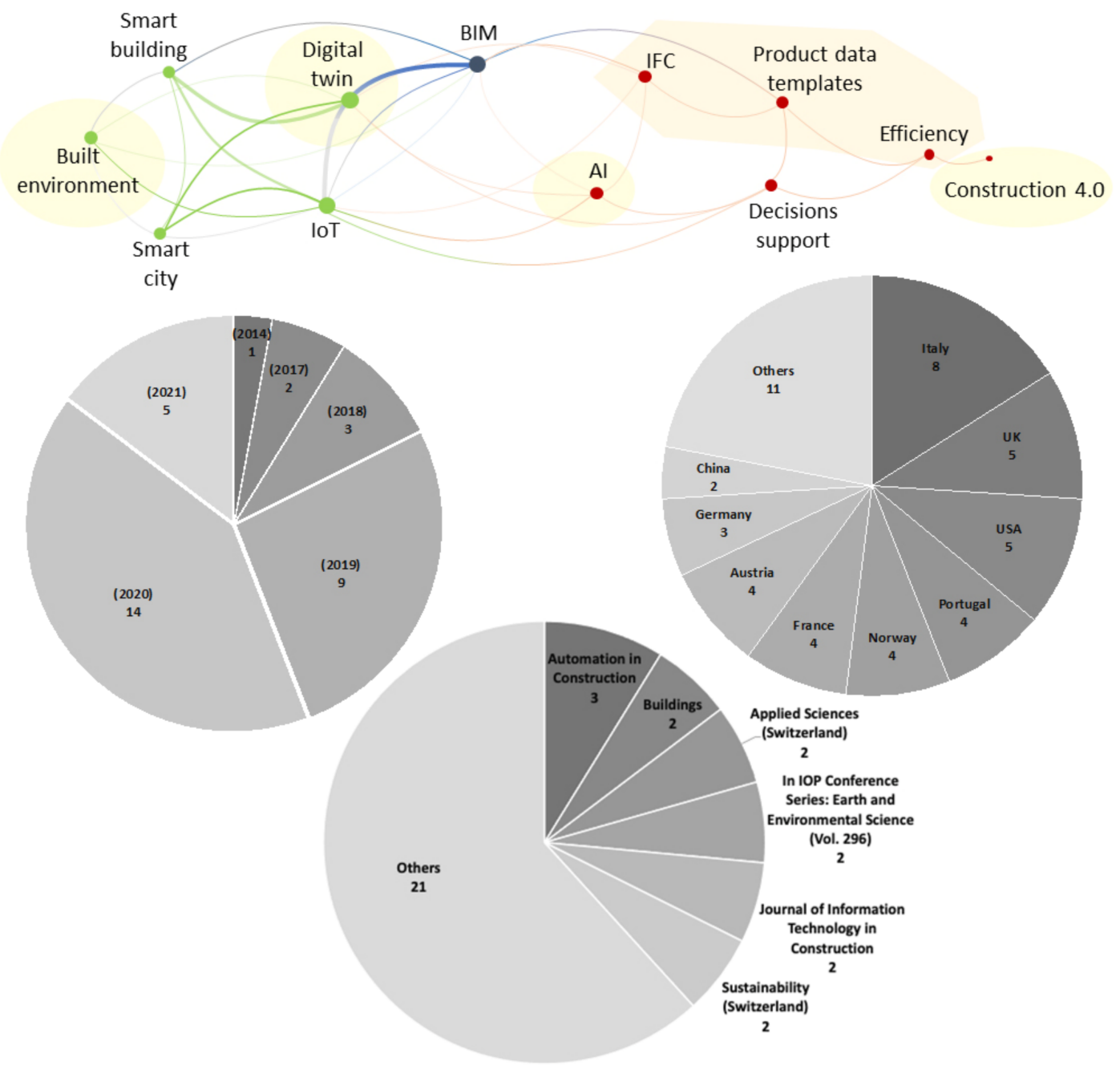

Figure 2. Network map of referenced keyword clusters and pie charts evidencing the years, countries, and origin in terms of journals or publication sources.

Table 2. The content of the selected publications (Scopus and WOS), in terms of digital solutions implemented (the concepts are marked with numbers, 1 for DDT—digital data templates; 2 for DBL—digital building logbook and 3 for DTC—digital twin construction). As well, the main research aim is identified.

\begin{tabular}{|c|c|c|c|c|c|}
\hline Reference & DDT $^{1}$ & DBL $^{2}$ & DTC $^{3}$ & Country & Main Aim Identified \\
\hline [16] & & 2 & & Italy & $\begin{array}{l}\text { To prove the effectiveness of a methodology to compute a } \\
\text { degradation index in an existing building. It is supposed to } \\
\text { use data and integrate this information from or into the } \\
\text { building logbook (nowadays, DBL). }\end{array}$ \\
\hline [17] & 1 & & & UK & $\begin{array}{l}\text { Orientation for a "level of development" (LOD) that } \\
\text { manufacturers should use to create their model element } \\
\text { product data, based on PDTs. }\end{array}$ \\
\hline [18] & & 2 & & $\begin{array}{l}\text { Norway } \\
\text { UK } \\
\text { Australia }\end{array}$ & $\begin{array}{l}\text { To test a "mixed methods approach centred on a case study building } \\
\text { in reviewing energy-performance attributes of BREEAM, the } \\
\text { Cambridge Work Plan and BRUKL". Findings indicate, "The } \\
\text { building's core functions were revealed to consume } 140 \% \text { more } \\
\text { energy than the building logbook estimate for the same needs." }\end{array}$ \\
\hline
\end{tabular}


Table 2. Cont.

\begin{tabular}{|c|c|c|c|c|c|}
\hline Reference & DDT $^{1}$ & $\mathrm{DBL}^{2}$ & DTC $^{3}$ & Country & Main Aim Identified \\
\hline [19] & 1 & & & Portugal & $\begin{array}{c}\text { A case study evaluated that, from available information from } \\
3 \text { different manufacturers, findings indicate that } 41-66-67 \% \text { of } \\
\text { information is missing to fulfil all product specifications. In } \\
\text { addition, there were few environmental parameters: } 5 \text { out of } \\
29 \text { were not provided by the environmental product } \\
\text { declarations (EPD). }\end{array}$ \\
\hline [20] & & & 3 & Korea & $\begin{array}{l}\text { A conceptualisation of an augmented reality (AR)-based } \\
\text { smart building and town disaster management system to } \\
\text { acquire visibility and to rescue occupants in cases of fire } \\
\text { disasters in buildings. }\end{array}$ \\
\hline [21] & & 2 & & Italy & $\begin{array}{c}\text { "The aim of the paper is firstly to set a Building Renovation } \\
\text { Passport (BRP) definition, to explore the potential role of a } \\
\text { voluntary scheme across EU as a key tool to help overcome } \\
\text { this information imbalance by providing all market } \\
\text { stakeholders". }\end{array}$ \\
\hline [22] & & & 3 & $\begin{array}{l}\text { The } \\
\text { Netherlands } \\
\text { Norway }\end{array}$ & $\begin{array}{l}\text { The main aim is to list and discuss "special challenges for } \\
\text { building digital twins for cyber-physical systems of systems } \\
\text { and IoT installations." }\end{array}$ \\
\hline [23] & & 2 & & Germany & $\begin{array}{c}\text { The authors stated that "in most cases data transactions (to } \\
\text { buyers, tenants, consultants or other actors) cause significant } \\
\text { loss of information while the issues associated with the } \\
\text { 'building passport' approach remains unsolved to date". } \\
\text { Based on that: "Information needs of actors along the life } \\
\text { cycle are analysed, and new information technologies (e.g., } \\
\text { blockchain) are discussed." }\end{array}$ \\
\hline
\end{tabular}

[24] 1 Italy

The proposition of a conceptual model for providing such structure for product data to facilitate product data management (PDM).

The authors present the ALDREN project (ALliance for Deep RENovation in Buildings): "ALDREN is a strategy to mobilise

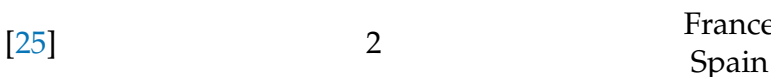
the construction industry by evaluating the financing viability and by highlighting collateral benefits to energy building renovation, as improving health and wellbeing." This is connected to the building renovation passport (BRP).

Development of a minimum environmental criteria for EPD

[26] 1 Italy (environmental product declaration) based on EN 15804 and ISO 21930. This can lead to environmental data specification on DDT.

The authors "propose a software architecture for creating and [27] 3 France managing unambiguous descriptions of a Smart Building, allowing its Digital Twin to be deployed."

[28] [29] 1

Test an APP to collect commercial buildings users' feedback to contextualise awareness to improve users' comfort and to reduce complaints.

Development of a BIM library for products data sharing, based on UNI/TS 11337-3:2015.

[30]

3 Germany

Demonstration of a prototype of a "Digital Twin for Smart Buildings in the context of suitable distributed system architectures", developed under the project SENSE.

The author argues that "the creation of the Digital Twins at the scale of Smart Precincts and Smart Cities requires the 
Table 2. Cont

\begin{tabular}{|c|c|c|c|c|c|}
\hline Reference & DDT $^{1}$ & DBL $^{2}$ & DTC $^{3}$ & Country & Main Aim Identified \\
\hline [32] & & & 3 & $\begin{array}{l}\text { UAE } \\
\text { USA }\end{array}$ & $\begin{array}{l}\text { The authors "propose an end-to-end digital twin conceptual } \\
\text { model that represents its complementary physical object from } \\
\text { the ground to the cloud. The paper presents the proposed } \\
\text { digital twin model's multi-layers, namely, physical, } \\
\text { communication, virtual space, data analytic and visualisation, } \\
\text { and application as well as the overlapping security layer." }\end{array}$ \\
\hline [11] & & & 3 & Portugal & $\begin{array}{l}\text { The conceptualisation of sensored construction sites focusing } \\
\text { the craft workforce performance monitoring. }\end{array}$ \\
\hline [33] & & & 3 & China & $\begin{array}{l}\text { The authors introduce and test a framework for an indoor } \\
\text { safety management system based on digital twins, integrating } \\
\text { building operating data and 3D indoor scenes. They also } \\
\text { tested the feasibility of using artificial intelligence and IoT to } \\
\text { define the types and levels of indoor danger. }\end{array}$ \\
\hline [34] & & & 3 & China & $\begin{array}{l}\text { The conceptualisation of digital twins for electric power } \\
\text { plants design and construction "taking BIM model as the } \\
\text { carrier and taking the data as the core". }\end{array}$ \\
\hline [35] & & & 3 & USA & $\begin{array}{l}\text { The authors realised a systemic review "to identify the } \\
\text { development of the emerging technologies facilitating the } \\
\text { evolution of BIM to Digital Twins in built environment } \\
\text { applications", finally proposing a framework for building } \\
\text { management based on digital twins. }\end{array}$ \\
\hline [36] & 1 & & & $\begin{array}{l}\text { Portugal } \\
\text { Italy }\end{array}$ & $\begin{array}{c}\text { "Aiming at a standardisation of the heritage information } \\
\text { content, developed a template for the different classes of } \\
\text { damage inspired by the concept of Product Data Templates } \\
\text { for new manufacturer's products." }\end{array}$ \\
\hline [37] & & 2 & & $\begin{array}{l}\text { Italy } \\
\text { France }\end{array}$ & $\begin{array}{l}\text { "The paper presents the ALDREN overall procedure with a } \\
\text { focus on the development of the Building Renovation } \\
\text { Passport and its application to an Italian office building". }\end{array}$ \\
\hline
\end{tabular}

Table 3. The content of the selected articles and theses (selected by the authors), in terms of digital solutions implemented (DDT—digital data templates—1; DBL—digital building logbook-2; DTC—digital twin construction-3) and the main research aims identified.

\begin{tabular}{|c|c|c|c|c|c|}
\hline Reference & DDT $^{1}$ & $\mathrm{DBL}^{2}$ & DTC $^{3}$ & Country & Main Aim Identified \\
\hline [38] & & & 3 & Australia & $\begin{array}{l}\text { Based on identified gaps in the literature, the authors } \\
\text { highlighted the challenges for research to implement } \\
\text { sensored construction sites. }\end{array}$ \\
\hline [39] & & 2 & & UK & $\begin{array}{c}\text { The conceptualisation of a framework for a digital record of } \\
\text { built assets (new and existing buildings) assuring data } \\
\text { traceability. }\end{array}$ \\
\hline [9] & & & 3 & France & $\begin{array}{c}\text { The main aim is to bring awareness about the necessity of a } \\
\text { unique and continuous digital twin model over different } \\
\text { phases (design, construction, and as-built) }\end{array}$ \\
\hline [12] & & & 3 & USA & $\begin{array}{l}\text { After review, enabling technologies and systems for smart } \\
\text { building, the author "argues that a mature adoption of IoT } \\
\text { technologies in the building industry is not yet realised and, } \\
\text { therefore, calls for more attention from researchers in the } \\
\text { relevant fields from the application perspective." }\end{array}$ \\
\hline$[40]$ & 1 & & & $\begin{array}{l}\text { Australia } \\
\text { Canada }\end{array}$ & $\begin{array}{l}\text { The conceptualisation of a framework for information flows } \\
\text { across an asset's life cycle. }\end{array}$ \\
\hline
\end{tabular}


Table 3. Cont.

\begin{tabular}{|c|c|c|c|c|c|}
\hline Reference & DDT $^{1}$ & DBL $^{2}$ & DTC $^{3}$ & Country & Main Aim Identified \\
\hline [10] & & & 3 & Norway & $\begin{array}{l}\text { The author conceptualised and surveyed a digital twin } \\
\text { maturity index to categorise different levels of digital twin } \\
\text { maturity. }\end{array}$ \\
\hline [8] & & & 3 & $\begin{array}{c}\text { Israel, UK, } \\
\text { Finland, USA }\end{array}$ & $\begin{array}{l}\text { The authors established the concept of a digital twin } \\
\text { construction, focusing on a sensored construction site and the } \\
\text { control of site activities based on planned schedules. }\end{array}$ \\
\hline [7] & & & 3 & $\begin{array}{c}\text { Luxembourg } \\
\text { UK }\end{array}$ & $\begin{array}{l}\text { "The paper reviews the multi-faceted applications of BIM } \\
\text { during the construction stage and highlights limits and } \\
\text { requirements, paving the way to the concept of a } \\
\text { Construction Digital Twin. A definition of such a concept is } \\
\text { then given, described in terms of underpinning research } \\
\text { themes, while elaborating on areas for future research." }\end{array}$ \\
\hline [41] & 1 & & & $\begin{array}{l}\text { Portugal } \\
\text { Norway }\end{array}$ & $\begin{array}{l}\text { "The paper updates and expands research on product } \\
\text { information management. Highlights how data is managed } \\
\text { by different stakeholders and the role of Data Templates as a } \\
\text { game-changer. These are found to be the standard structures } \\
\text { to enable and foster the lifecycle digital supply chain at built } \\
\text { environment level". }\end{array}$ \\
\hline [42] & & & 3 & $\begin{array}{c}\text { Italy } \\
\text { Switzerland }\end{array}$ & $\begin{array}{l}\text { The authors conceptualise a framework "exploiting the digital } \\
\text { twin approach to support the decision processes related to } \\
\text { sustainability through the whole building's life cycle". }\end{array}$ \\
\hline [43] & & & 3 & $\begin{array}{l}\text { Sweden } \\
\text { USA } \\
\text { Turkey }\end{array}$ & $\begin{array}{c}\text { Surveyed construction industry experts to investigate } \\
\text { cognitive digital twins (CDT) integration on life cycle-centric } \\
\text { applicability and interoperability, to provide decision } \\
\text { support. }\end{array}$ \\
\hline
\end{tabular}

Table 4. The content of the selected publications (selected by the authors), in terms of the digital solutions implemented (DDT—digital data templates-1; DBL—digital building logbook-2; DTC—digital twin construction-3), spectrum of research (world, EU, country, sector, subsector), strength (law, standard, guideline, strategy), and the main research aims identified.

\begin{tabular}{|c|c|c|c|c|c|c|}
\hline Reference & DDT $^{1}$ & DBL $^{2}$ & DTC $^{3}$ & Spectrum & Strength & Main Aim Identified \\
\hline [44] & & & 3 & $\begin{array}{l}\text { Country } \\
\text { [UK] }\end{array}$ & Strategic Plan & $\begin{array}{l}\text { Definition of strategic headings at country level for } \\
\text { the development of a more digital sector. }\end{array}$ \\
\hline [45] & & 2 & & EU & Guideline & $\begin{array}{l}\text { Overview of existing initiatives, contextualisation, } \\
\text { and conclusions or recommendations for future } \\
\text { developments. Building renovation passports can } \\
\text { be framed as the infancy of DBL. }\end{array}$ \\
\hline [46] & 1 & & & $\begin{array}{l}\text { Country } \\
\text { [UK] }\end{array}$ & Guideline & $\begin{array}{l}\text { Support DDT awareness and contextualisation } \\
\text { with BIM standards. }\end{array}$ \\
\hline [47] & 1 & & & $\begin{array}{l}\text { Country } \\
\text { [UK] }\end{array}$ & Guide/Strategy & $\begin{array}{l}\text { The realisation of the role of data in the } \\
\text { construction process and guidance towards } \\
\text { structuring data. }\end{array}$ \\
\hline [2] & 1 & 2 & & EU & Strategy & $\begin{array}{l}\text { When addressing resources, efficiency data } \\
\text { structures and traceability is present, meaning that } \\
\text { DDT and DBL are implicit in the document. }\end{array}$ \\
\hline [4] & 1 & 2 & & $\mathrm{EU}$ & Guideline & $\begin{array}{l}\text { The document presents and defines the processes } \\
\text { that need to take place prior to refurbishment } \\
\text { actions: the waste audits. This relies on data stored } \\
\text { and identified, leading to material inventories. } \\
\text { From an indirect viewpoint, DDT and DBL are } \\
\text { related to this topic. }\end{array}$ \\
\hline
\end{tabular}


Table 4. Cont.

\begin{tabular}{|c|c|c|c|c|c|c|}
\hline Reference & DDT $^{1}$ & $\mathrm{DBL}^{2}$ & DTC $^{3}$ & Spectrum & Strength & Main Aim Identified \\
\hline$[48]$ & 1 & 2 & 3 & World & Standard & $\begin{array}{l}\text { Regulation of processes/promotion of common } \\
\text { understandings. } \\
\text { The focus of the standard is BIM methodology. } \\
\text { DDT are BIM enablers, and DBL and DTC benefit } \\
\text { from BIM. The concepts are explored from an } \\
\text { indirect point of view by the document. }\end{array}$ \\
\hline [49] & 1 & 2 & 3 & World & Standard & $\begin{array}{l}\text { Regulation of processes and promotion of common } \\
\text { understandings. } \\
\text { The focus of the standard is BIM methodology. } \\
\text { DDT are BIM enablers, and DBL and DTC benefit } \\
\text { from BIM. The concepts are explored from an } \\
\text { indirect point of view by the document. }\end{array}$ \\
\hline$[50]$ & & & 3 & $\begin{array}{c}\text { Country } \\
{[\text { Germany] }}\end{array}$ & Guide/Strategy & $\begin{array}{l}\text { Industry awareness and disclosure of company } \\
\text { level visions (Siemens). }\end{array}$ \\
\hline [51] & & & 3 & $\begin{array}{l}\text { Country } \\
\text { [UK] }\end{array}$ & Guide/Strategy & $\begin{array}{l}\text { Capabilities awareness and strategic roadmap. } \\
\text { Centres on DTC but DDT and DBL are part of it. }\end{array}$ \\
\hline$[52]$ & 1 & & & World & Guide/Strategy & $\begin{array}{l}\text { The realisation of the role of data in the } \\
\text { construction process and how collaboration plays } \\
\text { an essential role in the improvement. }\end{array}$ \\
\hline [53] & 1 & & 3 & $\begin{array}{l}\text { Country } \\
\text { [Lux] }\end{array}$ & Strategic Plan & $\begin{array}{l}\text { Broad strategic document ranging from several } \\
\text { areas. From an indirect point of view, it approaches } \\
\text { DTC and DDT. }\end{array}$ \\
\hline$[1]$ & 1 & 2 & 3 & EU & Strategy & $\begin{array}{l}\text { Actions at EU level to achieve climate neutrality by } \\
\text { 2050. Among these actions, DDT, DBL, and DTC } \\
\text { are broadly mentioned. However, this document } \\
\text { frames all the others from the European } \\
\text { Commission that are mentioned here. }\end{array}$ \\
\hline$[3]$ & 1 & 2 & & EU & Strategy & $\begin{array}{l}\text { Among the actions for the Renovation Wave are } \\
\text { the DBL and the ability to have more data related } \\
\text { to construction products, i.e., DDT. }\end{array}$ \\
\hline [54] & 1 & & & EU & Standard & $\begin{array}{l}\text { A BIM-related standard that details processes from } \\
\text { ISO } 19650 \text { and focuses on data for purposes: level } \\
\text { of information need. }\end{array}$ \\
\hline [13] & 1 & & & World & Standard & $\begin{array}{l}\text { Concepts and principles awareness and } \\
\text { developments towards a joint understanding of the } \\
\text { topic. }\end{array}$ \\
\hline [55] & 1 & & 3 & $\begin{array}{l}\text { Country } \\
\text { [UK] }\end{array}$ & Standard & $\begin{array}{l}\text { Standard document to foster interoperability } \\
\text { requirements. Touches from the indirect point of } \\
\text { view in DDT and DTC. }\end{array}$ \\
\hline [56] & 1 & 2 & 3 & World & Guideline & $\begin{array}{c}\text { This awareness document explores interoperability } \\
\text { issues and, from an indirect point of view, deals } \\
\text { with the three topics of research. }\end{array}$ \\
\hline$[57]$ & 1 & & 3 & $\begin{array}{l}\text { Country } \\
\text { [NZ] }\end{array}$ & Overview/Strategy & $\begin{array}{l}\text { Overview of existing initiatives, contextualisation, } \\
\text { and conclusions or roadmap }\end{array}$ \\
\hline$[5]$ & & & 3 & World & Guide/Strategy & $\begin{array}{l}\text { Industry awareness and disclosure of entity vision } \\
\text { on digital twins. }\end{array}$ \\
\hline$[14]$ & & 2 & & EU & Overview/Strategy & $\begin{array}{l}\text { Overview of existing initiatives, contextualisation, } \\
\text { y and conclusions or recommendations for future } \\
\text { developments on harmonised DBLs. }\end{array}$ \\
\hline
\end{tabular}


Table 4. Cont

\begin{tabular}{|c|c|c|c|c|c|c|}
\hline Reference & DDT $^{1}$ & $\mathrm{DBL}^{2}$ & DTC $^{3}$ & Spectrum & Strength & Main Aim Identified \\
\hline [58] & 1 & 2 & & USA & Guide/Strategy & $\begin{array}{l}\text { COBie is a way to transfer BIM data into FM } \\
\text { systems. This relates with the three topics as DDT } \\
\text { enables a streamlined COBie and this can provide } \\
\text { structured data to DBL, therefore supporting DTC. }\end{array}$ \\
\hline [59] & & & 3 & EU & Overview/Strategy & $\begin{array}{l}\text { Roadmap to implement a smart readiness indicator } \\
y \quad \text { for building. This topic is related to DTC } \\
\text { ecosystems and namely in buildings. }\end{array}$ \\
\hline [6] & & & 3 & EU & Overview/Strategy & $\begin{array}{l}\text { Overview of existing initiatives, contextualisation, } \\
\text { and potential future headings. }\end{array}$ \\
\hline
\end{tabular}

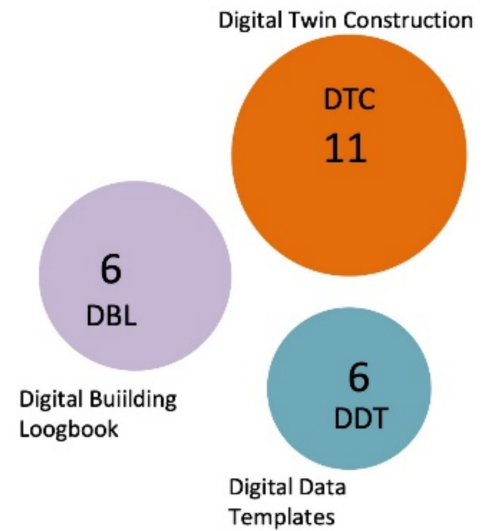

Bases on Table 2. The content of the 23 selected publications (Scopus and WOS)

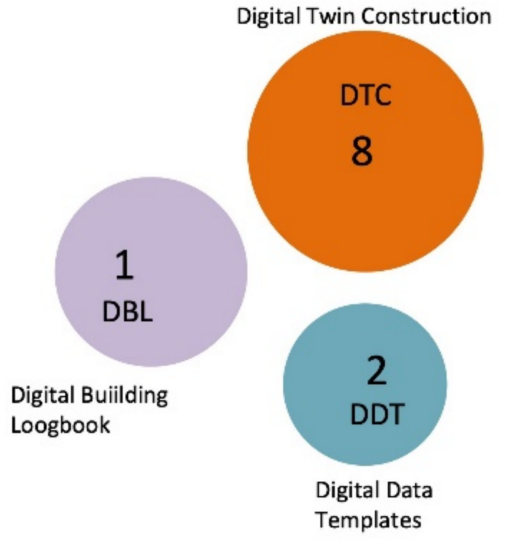

Bases on Table 3. The content of the 11 selected articles and thesis (by Authors)

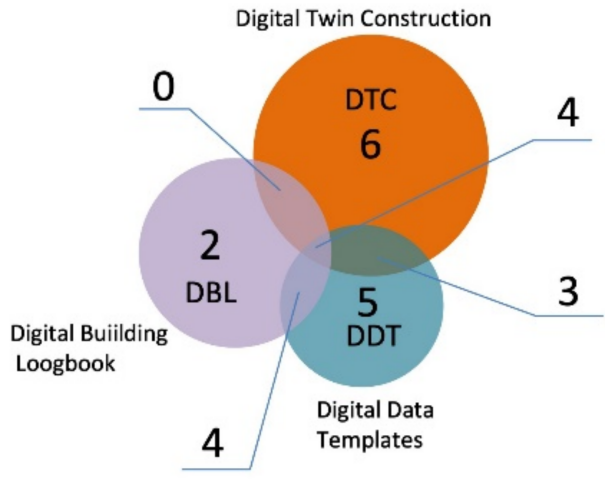

Bases on Table 4. The content of the 24 selected publications (by Authors)

Figure 3. Visual overview on the concepts results for each one of the tables.

\subsection{Digital Data Templates}

ISO 23387 states that: "Data templates will enable construction project stakeholders to exchange information about construction objects through an asset life cycle, using the same data structure, terminology and globally unique identifiers to enable machine-readability. Data templates should be standardised and made available across the built environment sector through data dictionaries based on ISO 12006-3:2007. Data templates should be used in conjunction with Industry Foundation Classes (IFC) in ISO 16739-1 to enable and support open BIM processes." [13] (p. 5).

It is undeniable that, in the short term, it will not be possible to have data templates for all products and solutions. Therefore, the use or adoption of these structures should be prioritized in accordance with a stakeholder's objectives. Cost is an essential factor for all economic activities. From a manufacturer or contractor point of view, products with high relevance in terms of cost (acquisition or life cycle, or both) are found to be more relevant to disclosure or to be set on a construction project using data templates. The manufacturers are concerned about their model element product data [17] and structure product data to facilitate product data management (PDM) [24].

Following the construction trends, it is possible to evidence that products with high contributions to the built environment efficiency at energy, $\mathrm{CO}_{2}$, or waste levels can be at the forefront. Given the broad scope of existing products and from manufacturers' perspective, the standard solutions, either in terms of characteristics or sales volume, are also found to be the ones with the highest added value. Many construction products still lack in specifications (information or data), mainly related to environmental requirements [19]. A minimum environmental criteria for EPD should be targeted [26]. A sustainable and circular economy should be data-driven $[1,2,53]$. Building sustainability assessment methods 
(BSAM) frame the concepts of sustainability in buildings, e.g., LEED (2019), DGNB (2019), and BREEAM (2019) [60]. Life cycle assessment (LCA) methodology seeks to evaluate the buildings environmental impacts, taking an advance on the information from the environmental product declarations (EPDs) [60-69]. The lack of standard data structures inhibits the collection and exchange of information about buildings performances, durability, and environmental indicators [29].

The development and adoption of data templates is aligned with the existence of reliable sources of information to appoint or characterise the products, systems, or objects properties. It is vital to understand the role of data in the construction process and in guidance towards structuring it [47], including building renovation and heritage [3,36]. These rely on standards, namely harmonised standards, regulations, environmental declarations, facility management properties, and interoperability tools such as IFC or buildingSMART Data Dictionary (bsDD). The bSDD is an online service that hosts classifications and their properties: allowed values, units, and translations [70]. The bSDD allows linking between all the content inside the database. It provides a standardised workflow to guarantee data quality and information consistency. The BIM standards and libraries are fundamental for DDT awareness and interoperability $[13,29,46,48,49,52,54-57]$. For example, Uniclass 2015 may provide a standard classification for DDT upscaling to the creation of digital twins [31].

Product life cycle management (PLM) relies on data and on the ability to use it and trace it through the life cycle. Model-based definition (MBD) is a way to structure visions of the data to make it more comprehensive and useful for different stakeholders across the same life cycle. It is vital to map assets' life cycle information flows [40]. These terms (PLM and MBD) overlap with many others. Without neglecting the need for a streamlined awareness of these concepts, it is essential to realise that, to work better, these concepts require standardised digital data. If this is not the case, different concepts expressing the same properties will be managed differently and will be missing or will have to be interpreted alongside the construction life cycle.

A simple example can be used through the use of different terminology to express the insulation level of two different products. One used for the roof and the other for the exterior wall. The development of thermal analysis will have to rely on the ability to identify those nomenclatures and link them to the verification that is being made. In addition to errors, this translates into re-work, interpretation, and manual effort developed by one or more stakeholders. Yet, this interpretation might not work through the life cycle as when new stakeholders come in, their understanding might be different, leading to a different interpretation and therefore, result. DDT are structured and meant to overcome these potential issues by setting universal or machine-readable properties to be used from the manufacturing process to the end of the construction life cycle, with the ability to be used and managed in a project context by different stakeholders.

The construction industry is a priority domain in the action plan for circular economy in Europe because it is among the most significant sources of waste [2]. It is an important goal to efficiently use resources to reduce overall environmental impacts, throughout the buildings' life cycle. The waste audit is a specific action set to occur before the demolition or renovation of buildings and infrastructures. This must be foreseen within a project planning in order to detail and quantify the types and amounts of construction products that will be deconstructed or demolished and to issue recommendations on their future handling [4].

At this point, it is essential to highlight that the design and construction phases play an essential role in the building life cycle. Their purpose is to materialise a built object that is going to be used. Through design and construction, different products are brought together to accomplish several goals in terms of performance, and to produce a compliant built object. By contrast, the longest phase in the building life cycle is the use phase, where components are maintained, replaced, upgraded, and so on. To perform these activities, specific needs for data are required. As mentioned, data templates are structured based on 
facility management properties - properties that are of value to the use phase-and COBie is designed to systematise and capture use phase data [58].

The key for data templates relies on the ability to use said properties from the very beginning. Or, set an unbreakable link between the properties which use different concepts. The ability to use the original source brings significant gains in terms of work but mainly, it brings gains in terms of achieving a long-term understanding of the meanings and terms within the industry. Product information management is a challenge as data dealing involves different stakeholders spreading throughout the construction process. Data templates help solve this issue and are envisaged as a game-changer [41]. Additionally, it is possible to envision new functions for coordination of product data. The response in a specific company, as a manufacturer or contractor, by the management of the data templates-related information could be called the data template manager. When addressing the construction process, the responsibility for identifying the required data, data reliability analysis and evaluation of its source of truth or consistency in a specific phase or across the construction process phases could be defined as an information consistency manager.

\subsection{Digital Building Logbooks}

The process of collecting, capturing, storing, and transferring information related to built objects is path-dependent. Responding to advances in technology, the disciplines have incrementally innovated their respective processes, either in terms of data related with soil, characteristics of the built objects, its elements, or components, among others. But they have done so within their own hierarchical silos. Partly, due to lack of uniform information management strategy. In addition, partly because of lock-in effects present in each discipline, such as dependence on a certain set of methods, software, and tools. The effect increased and isolated growth in complexity within each discipline. With the secondary effect of deepening the chasm between the information silos making crossdiscipline information transactions more complex.

Cadastral data sharing has been a growing concern, as it is digital, it aims to gather more data that was structured differently and aims to set a common framework [71]. At built objects level, there are also new concerns. From the ability to use the captured data to perform asset management [58], assess energy performance [18], or the buildings condition assessment [16], they all introduce new issues for data, placing a higher demand on data management. The building renovation passport initiative was launched with the objective of collecting and set up relevant data for these and other uses, when a building was [25] submitted to a large refurbishment. This launched the basis for future directions on the identification of potential uses for data, as well as existing systems and structures working in different countries. The growing requirements, namely those related to sustainability, the flaws in terms of traceability, and the increasing bet on digitalisation, led to new initiatives focused on the development of a common framework to gather all buildings relevant data-the digital building logbook.

According to the EU (2020), the DBL "can include administrative documents, plans, description of the land, the building and its surrounding, technical systems, traceability and characteristics of construction materials, performance data such as operational energy use, indoor environmental quality, smart building potential and lifecycle emissions, as well as links to building ratings and certificates. As a result, it also enables circularity in the built environment. Some data types stored in the logbook have a more static nature, while others, such as data coming from smart meters and intelligent devices, are dynamic and need to be automatically and regularly updated. A digital building logbook is a safe instrument giving users control and access to third parties, respecting the fundamental right to protection of personal data. Data may be stored within the logbook and/or hosted in a different location to which the logbook acts as a gateway." [14] (p. 5).

This new vision positions DBL as an information container or "digital shadow" that must be fed with data from several sources throughout the construction process. Likewise, it provides data for the development of analysis and processes. There are different types of data-static data or dynamic data, either updated only from time to time or continu- 
ously updated, respectively. This requires an interaction between this digital information container and the physical sensored built object.

\subsection{Digital Twins in the Construction Industry}

The conceptualisation of digital twins into the construction industry is scattered. However, it is attached to the concept of Industry 4.0 and mainly concerning to IoT devices, big data and artificial intelligence [7-10,22,32]. As stated before, to put it in the context of the CI, it is nominated in this research as DTC-digital twin construction.

A digital twin is a platform that integrates data and different systems, making it a system of systems (SoS) [22] It can be visualised into multi-domain ontologies [27] or multi-layers [32]. An example is through the use of the WoT thing description standard from W3C [22,30]. Borth et al. (2019) highlight challenges of SoS as fraud detection, data interoperability, and "extra costs in updates and upgrades caused by the SoS' geographical distribution" [22] (p. 169). BIM is a vector of building data and integrating it with IoT is crucial to many solutions, such as indoor safety management [33], digitalisation [34], and visual representations [35]. IoT devices incorporation into buildings should target sustainable indicators assessment [42] into a total life cycle management [43]. However, IoT technologies implementation in the construction industry should be further explored in both academic and industrial fields [12].

Over the following subheadings, it is evidenced that DTC concepts mainly address the data interaction between the physical and virtual assets, the sensing technologies applied in both construction and in-use phases, and the possible distinguished levels of evolution of a DTC.

\subsubsection{Concepts, Uni/Bi-Directional Data Interaction, and Incremental Implementation} Phases

A concept of the digital twin evolution was presented at the First Building Digital Twin International Congress on 27th May 2021 [72]. Digital twin is up scaled following five stages regarding the increased information evolution into a physical to virtual maturity, as follows: $0=$ traditional, $1=$ transitional, $2=$ conceptual, $3=$ replication and, $4=$ front running [72]. There is a common understanding of an evolutive path to a fully connected digital twin. The way the data flows (manual or automatic) between the physical and digital objects can indicate a level of evolution of the DTC [9]. There are three evolutionary steps:

- Digital model (manual data flow between physical and virtual objects) [9]. As an example, there is a designed 3D model of a building that corresponds to the physical element, and when some change is made on the physical building, it is updated in the digital environment.

- Digital shadow (with an automatic data flow from physical to virtual and manual data flow from digital to physical objects) [9]. As an example, a sensored site or building where the data is collected but the system is not able to interact and take action into the physical space.

- Digital twin (with bi-directional data flowing between physical and virtual objects) [9]. For example, a smart building with IoT collecting data from the built environment (e.g., temperature and amount of people in each room) and adjusting the HVAC systems.

Boje et al. (2020) indicates a progressive evolution approach for the DTC [7]. In this concept, the monitored platforms, that is the physical element, must be sensored. Generation one of a DTC has endued bi-directional data flow with some degree of report and analysis capabilities [7]. In the first generation, the virtual system just acts on the physical one when emergency procedures rules are achieved [7]. The second generation is considered an intelligent semantic platform and is based on a bi-directional data interaction [7]. It integrates IoT devices and limited AI to enable virtual simulations and predictions, limited to actions on the physical twin (e.g., on security, safety, and energy 
consumption) [7]. Finally, in the third generation, a full DTC semantic is achieved [7]. The full DTC is able to act from the virtual twin to the physical environment in a fully autonomous decision-making way, just requiring human supervision [7]. This full DTC achieves a "self-reliant, self-updatable and self-learning" platform [7].

Sacks et al. (2020), as an example of Boje et al. (2020), just consider the "starting point" of a DTC when this is sensored-based (IoT devices). Meaning, when allowing a bi-directional data interaction between the physical and virtual world $[7,8]$. For the case of a building, it would be, at minimum, a smart building (see details on following Section 3.4.3). In addition, Sacks et al. (2020) emphasise the tools of a DTC in the construction phase, highlighting the need for sensored construction sites (see details on following Section 3.4.2) [8].

Fjeld (2020) conducted fifteen in-depth interviews with Norwegian stakeholders from the architecture, engineering, construction and facility management fields [10]. As observed, $60 \%$ of the respondents indicate that machine-readable data is essential to the DTC [10]. However, $36 \%$ pointed that sensing technologies are not essential to the development of the DTC [10]. Recently, there is a convergence of several authors regarding a vision that leads to an incremental DTC. This is congruent with the industry practice that ends up implementing digitalisation processes in phases. Therefore, a concept of a DTC that grows over time can be validated. DTC degree of automation can be set over four spectrums, as follows: (i) input, (ii) output, (iii) sub-programs and rules of actuation, (iv) access and security [10].

- Input-(a) manual, (b) semi-automated, and (c) automatic [10].

- Output-(a) manual, fully customised, (b) semi-automated, mixed, and (c) automatic, fully predefined [10].

- Sub-programs and rules of actuation-(a) manual, fully customised, (b) semi-automated, mixed, and (c) automatic, fully predefined [10].

- Access and security-(a) full access and (b) limited [10].

- Fjeld (2020) proposed an accumulative and progressive six-level “Digital Twin Maturity Index (DTMI)" [10]:

- Level 100-static twin (no integration from the physical to the virtual environment) [10].

- Level 200-detailed twin (semi unidirectional integration from the physical to the virtual environment) [10].

- Level 300-as-built twin (unidirectional integration from the physical to the virtual environment) [10].

- Level 350-responsive twin (limited bidirectional integration from the physical to the virtual environment) [10].

- Level 400-adaptive twin (semi bidirectional integration from the physical to the virtual environment) [10].

- Level 500-intelligent twin (fully bidirectional integration from the physical to the virtual environment) [10].

So far, CI strategic plans targeting smart cities and a digital economy were scaled into market opportunities phases $[6,44,51]$ to transponder the poor sector performance in digitisation [50]. Finally, a DTC should be performed along the building's life cycle, increasing technical and financial performance, targeting sustainable goals $[5,42,43]$. One example is the smart readiness indicator (SRI) for the energy performance of buildings directive (EPBD) [59].

\subsubsection{Sensored Construction Sites}

The main goal of a sensored construction site is to assess the work-in-progress (WIP) performance. This leads to electronic monitoring of the products, equipment, and workers [11] — that is, the "physical components" [7]. One example is the acquisition of data from the physical environment to the virtual for optimised scheduling [7]. PDCA (plan, do, check, and act) measures the project schedule versus the actual status [8]. It is in the construction phase that the sensors to monitor the building in the use phase will be 
implemented. Some of them might gain use earlier, during construction, as part of the supporting tools for the sensored construction site. A significant part of the construction phase data is connected to workforce. Therefore, the human-data interaction becomes a crucial vector of information [73].

Several key performance indicators (KPIs) are related to a project performance and can be sensored and monitored, mainly concerning the well-known constraints (cost, schedule, quality, scope, safety, and environment) [11,38,74,75]. LCA approaches quantify environmental impacts into the construction process phase, accounting for emissions in the transport (A4) and construction or installation processes (A5) [76]. For example, on-site craft workforce potentially generates a higher volume of emissions, accounting for nearly more than $33 \%$ wastewater and emit $1185 \%$ more CO2 than office workers [77]. "The digital skin of the future pervasive construction site is composed of a system of seamlessly networked sensors, actuators, displays and computational elements, with embedded intelligence and advanced digital applications, attached to various objects" [38] (p. 188).

\subsubsection{Smart Buildings}

A smart building is based on embedded IoT to collect data from the physical environments, to be stored and processed in a responsive virtual scenario [12,42]. In addition, the main goal is to achieve a building higher performance in terms of costs, environmental emissions, and indoor comfort, etc. [12,20,28,42,43]. Towards a network of smart buildings or infrastructures and users, the intention is to establish the smart cities and the smart building environment. The data collection and processing can occur in many dimensions, such as:

- $\quad$ Safety and security $[20,22,73]$.

- $\quad$ Assets and energy management [7,12].

- User experience [28].

- Building life cycle assessment [42,43].

The facility management task is boosted by the DTC $[42,43]$. More than information traceability, it increases response time and efficiency [12]. On a DTC platform, maintenance, repair, and replacement lead times may be shorter and implementing activities on schedule can better assure the product's or system's lifetime [12]. The continuous monitoring of energy consumption may indicate variabilities not planned and can demand actions to review systems, contributing to achieving the pre-established sustainable goal [18,42].

\section{Discussion and Concepts}

\subsection{DDT, DBL and DTC Overlap-Data-Centric Construction}

The review provides understanding on the characteristics of the concepts under research, making possible the discussion and conceptualisation on its potential overlaps.

Digital data templates (DDT) are standardised structures aimed to capture construction objects characteristics. Data is made machine readable, acting as an enabler or facilitator for information exchange and data management throughout the object life cycle. If we consider an example of DDT for an external thermal insulation composite system (ETICS) solution in a private building, this solution characteristics will be "born" during the design phase, gaining reference values or even specific values related to a commercial solution. During the design phase, they are used to develop design-related analyses and evaluations, supporting also the specifications, budget estimates, and drawings. These are validated or changed according to the solution that is placed on-site during the construction (additional analysis for compliance check can be made) and it will last during the use phase until the moment where maintenance actions will introduce changes on some of the characteristics or when it comes the moment for replacement. Therefore, corresponding to the solution life end.

The digital building logbook is defined as a framework for all relevant buildings' information storage, meaning that, in broad sense, it should be able to receive, store, exchange, trace and update all data related to buildings and its components. Structuring 
the data to make it machine readable is mandatory. These functionalities can either be defined on the framework for DBL's or come from other tools to which the DBL links or exchanges and receives data. The DBL ranges several types of data, including that from the geographic position where the building is going to be built to all the construction products characteristics relevant to perform asset management. In this sense, DBL are built during the design phase, providing and receiving relevant data. Information exchange protocols and traceability are required right from the start. Using the abovementioned example, the DBL can trace the ETICS solution evolution throughout the construction life cycle. From the definition of the relevant characteristics to consider from the DDT to the definition of the aimed values, values or data from commercial solution appointed during design (if applicable, depending on the procurement route), and values or data from the commercial solution set on site and characteristics update from maintenance actions. From this, it becomes clear the relationship and overlaps between DDT and DBL.

The digital twin construction is a platform integrating data from different systems. It is the data integrator combining the physical object and the digital mirror. By being an SoS, a digital twin might be a quite simple thing or a rather complex one. An example is to consider the allocation of a sensor and communication protocol to monitor and control how much electricity is being consumed in a building. For this purpose, the physical twin characteristics are ignored with exception of the sensor monitoring energy consumption. The digital twin can be a dot or a volume, geo-referenced or not, with a list of daily, monthly, or instant electricity consumption. Or it is possible to increase the complexity, making the digital twin construction combine multiple systems to perform additional operations, such as analysis of the real thermal behaviour of a building compared with the design analysis and assumptions. In these cases, the twin must have all the energy efficiency data and results in order to compare with data collected from sensors operating in the physical twin. DDT and DBL are information providers for analytics and DBL is the virtual receiver of data being collected by the various systems of the physical object.

From a data-driven perspective, to boost digital twins maturity levels, a strong relation between these concepts becomes clear. There is a significant amount of data structured by each concept and information that must be exchanged between them. The abovementioned examples focus on specific features that can be explored individually by each concept but already pointing to this relationship, supporting, therefore, the conceptualisation of the Digital data-driven (D3c) concept, presented in Figure 4.

To exemplify how this relation is natural and contributes both to developments in sustainability and digitalisation, we consider a commonplace example consisting of sensored lightning system in residential buildings common areas. Consisting of regular light fixtures and sensors replacing the traditional light switches, these common systems are installed with the purpose of decreasing the energy consumption. They fulfil their purpose, operating as isolated systems, meaning they do not exploit any potential added value that could result from an improved interconnection.

Considering this same system, but in the context of a smart building, where there is a functional link between the physical and the digital twin, this facilitates data flows to monitor, as an example, the number of times that each sensor switches on the lights in one day. This means that this system becomes a live SoS inside the DTC. Through its sensors data is sent to a predefined information container for analysis (A). This container should be the digital building logbook. DBL is the information container for the product characteristics that compose the system, namely the light fixtures and sensors, among others. These products characteristics derive from the design and construction phase and as mentioned, should be structured following DDT framework (B). DBL's main purpose is to store data. The analysis of specific stored data can provide useful inputs for the building life cycle, for example in evaluating the adequacy of solutions supporting the current use pattern or the resources and time required to perform replacement or maintenance operations. The existing light fixture and sensor might, or might not, be the most suited for the situation. The outcome of having this data enables near real time evaluations and the 
establishment of specific requirements in future solutions (to be observed in DDT) when replacement occurs $(\mathrm{C})$. In addition, part of this data will support circular practices as the system constituents are clearly identified and the reuse or recycling ability or type of waste constitute direct information that can be instantaneously delivered.

\section{Digital-Data-Driven}

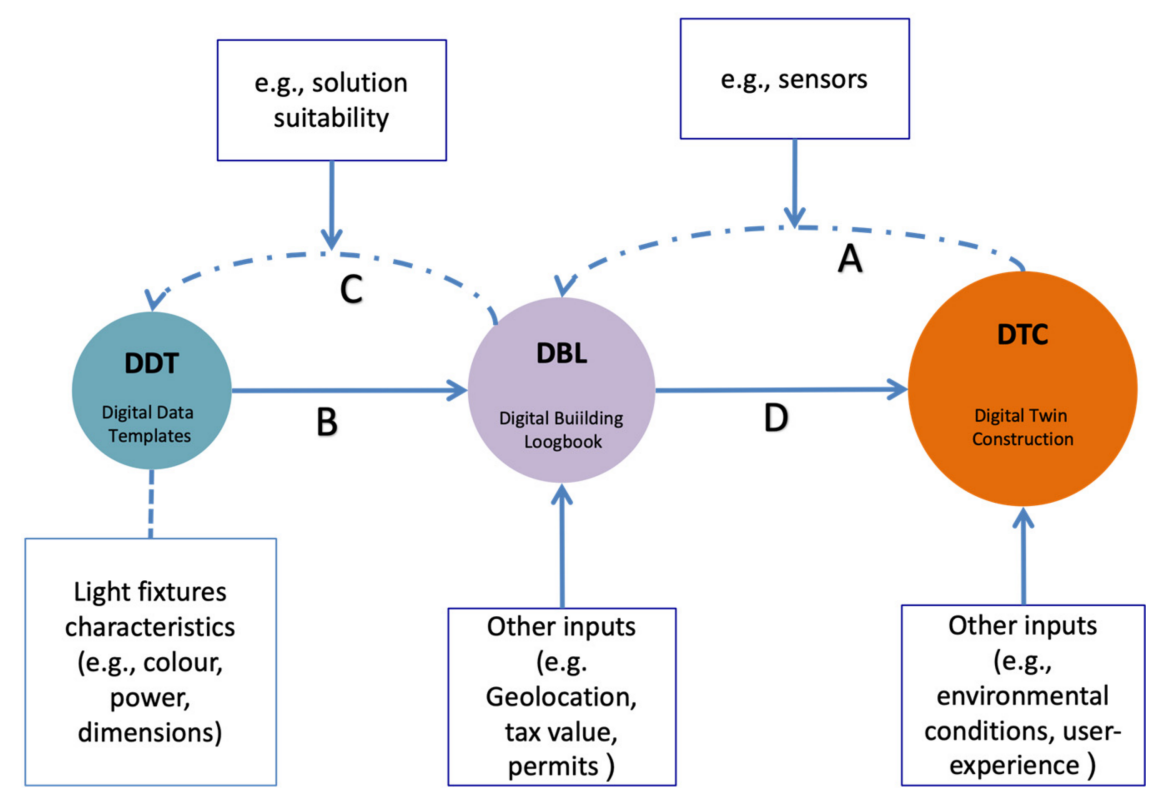

Figure 4. DDT, DBL, and DTC enabling a digital data-driven concept-D3c (V.1.0).

Through the incremental adoption of DDT and DBL an isolated system can be transformed into a system that is part of the SoS that constitutes the digital twin construction (D). Given this, the next section explores and conceptualises how DDT and DBL contribute to an incremental vision of the DTC.

\subsection{Incremental DTC Conceptualisation with DDT and DBL}

Figure 5 presents the conceptualisation of an incremental digital twin for the CI. Based on the literature review, a seven-level, incremental twin is set and classified following specific aspects elected to each level. In the context of this research, the sequence and overlapping of DDT, DBL, and DTC are framed as part of the conceptualisation. The analysis of the works developed by several authors, this model is primarily based on the work of Fjeld (2020) [10], whose broader matrix covers all different approaches [7-9]. In this conceptualisation, an additional layer was introduced to the level's matrix, setting a split into two different levels. One concerning the "as-built" process and the other when inserting IoT by understanding that, nowadays, most corporations lack the maturity to implement both simultaneous, mainly IoT. In addition, data dimensions and amount significantly increase when sensoring is brought to the system. It is essential to emphasise that by being an incremental model, the most advanced levels integrate the elements of the lowest levels, and when in the future companies achieve a higher digital maturity, these levels will be more integrated and will be played together. Next, each level is detailed, as follows:

- Static twin (Level 100) [10]: the first approach from most of the CI stakeholders to digitalisation is through BIM, mainly focusing on 3D modelling. As stated before, at this level, there is no integration from the physical to the virtual environment [10]. This static twin is a graphical representation from the physical to the virtual-a starting point into a DTC. At this stage, it is essential to increase the focus on the information, seeking machine-readable data to achieve interoperability, enriching information 
details to move to the next level. The expected outcomes are 3D representations of the physical assets, where the software used to perform the model can provide IFC formats to be used by other type of software. For example, a company has a 3D model of a single house in Autodesk Revit and is able to export it in an IFC format. Yet, the model will have geometrical information of a wall, but does not have alphanumerical information about the type of wall, e.g., masonry, concrete, or drywall. At this level the data is only related to the building design.

- $\quad$ Detailed twin (Level 200) [10]: the company's philosophy on BIM is enriched at this level, targeting a more detailed information management approach. Products' specification data should be electronically available. A partly unidirectional integration from the physical to the virtual environment is based on data input from the project's products specifications. However, DDT are crucial to assure data traceability and to obtain digital data to move to the next level. More outcomes are possible. For example, a full or partial bill of quantities (BoQ) for some products can be extracted based on assets' detailed information. In addition, building sustainability assessment methods can be performed (e.g., LEED, DGNB, or BREEAM). Following the last example, a single house 3D model has assets detailed information (possibly powered by DDT), and the company is able to realise the products amounts needed to build it. In addition, with this detailed data, it is possible to estimate the emissions of the project for its whole life cycle. Data now is related to the products that will "form" the built object.

- As-built twin [10] (Level 250): at this level, there is still a unidirectional integration from the physical to the virtual environment [10]. Where the as-built information based on the construction phase is retrofitted to the models. Conventionally, such information is manually ratified or rectified in the models. All information regarding the products and processes of the construction phase must be catalogued. In most cases, this information is partially archived in physical format (paper) and digitised (files containing, for example, pdf files). Again, using digital data, it will be possible to review the DDT and establish a digital building logbook (DBL). The primary outcome at this level is an updated information database concerning the project. Nowadays, an "as-built" process is a regular activity that must be performed. In the future, it will be easier to accomplish it using digital data and through sensored construction sites. For example, at this level, the cradle to handover emissions can be measured, and the expected emissions for the following phases, as use and end of life can be reviewed. Data is concerning the "as-built" building and, also, can be related to the project performance.

- $\quad$ Sensored twin (Level 300): keeping in mind that it is an incremental model, after having a virtual twin populated with digital data concerning buildings products (specifications and "as-built"), it becomes possible to start taking advantage of IoT systems to have sensored sites and a future smart building. At the three first levels, data processing may depend on people to operate systems and provide information. By establishing the sensing of sites, processes previously carried out by people, such as creating the "as-built", can be carried out more autonomously. Based on IoT sensors and systems, a more autonomous bidirectional integration from the physical to the virtual environment becomes possible. A vast number of outcomes can be achieved due to the implementation of IoT. The greater the number of elements sensed (e.g., workers, users, products, equipment, and environmental conditions), the greater is the amount of information and the possibilities for analysis. Sensoring increases the amount of data collected. In this level, the data is related to the building (assets), people, project performance, and environment conditions. For the following levels, the data collected is still at the same dimension. However, in each level, the processing and the autonomy of the twin is increased.

- $\quad$ Responsive twin (Level 350) [10]: IoT devices collecting data from the physical environment in an autonomous way, will provide a significant amount of data in near real-time. In the virtual space, through systems, it becomes possible to operate actions 
on the physical twin based on pre-established rules or by the initiative of an operator. A limited bidirectional integration from the physical to the virtual environment is possible [10]. After taking control of the physical twin, it will allow actions, such as assessing temperature, electricity consumption, opening and closing doors and windows, and turning on or off equipment and systems. This stage is the starting point for the development of the rules and algorithms for a more advanced and smarter twin.

- Adaptive twin (Level 400) [10]: with a more significant amount of data and the analysis or learning of the actions and operations carried out in a more responsive first phase, it is possible to develop more confident and precise algorithms, as well as rules for autonomy. In this context, the development of a system capable of simulating scenarios and a high capacity for process automation is possible. However, human evaluation is still needed to verify machine decision-making, mainly to calibrate the system. So, it is possible a semi-bidirectional integration from the physical to the virtual environment [10].

- Intelligent twin (Level 500) [10]: finally, the incremental learning will make possible the development of a twin fully autonomous platform. Where is played a fully bidirectional integration from the physical to the virtual environment [10]. That evolutive development will allow solid and tested algorithms to avoid bias and errors and increasing safety and accuracy. A self-learning and self-regulating twin system will play corrective and preventive actions to increase buildings performance [10]. Human interaction is not requested [10], although some compliance assurance should be performed time to time to verify the DTC systems performance.

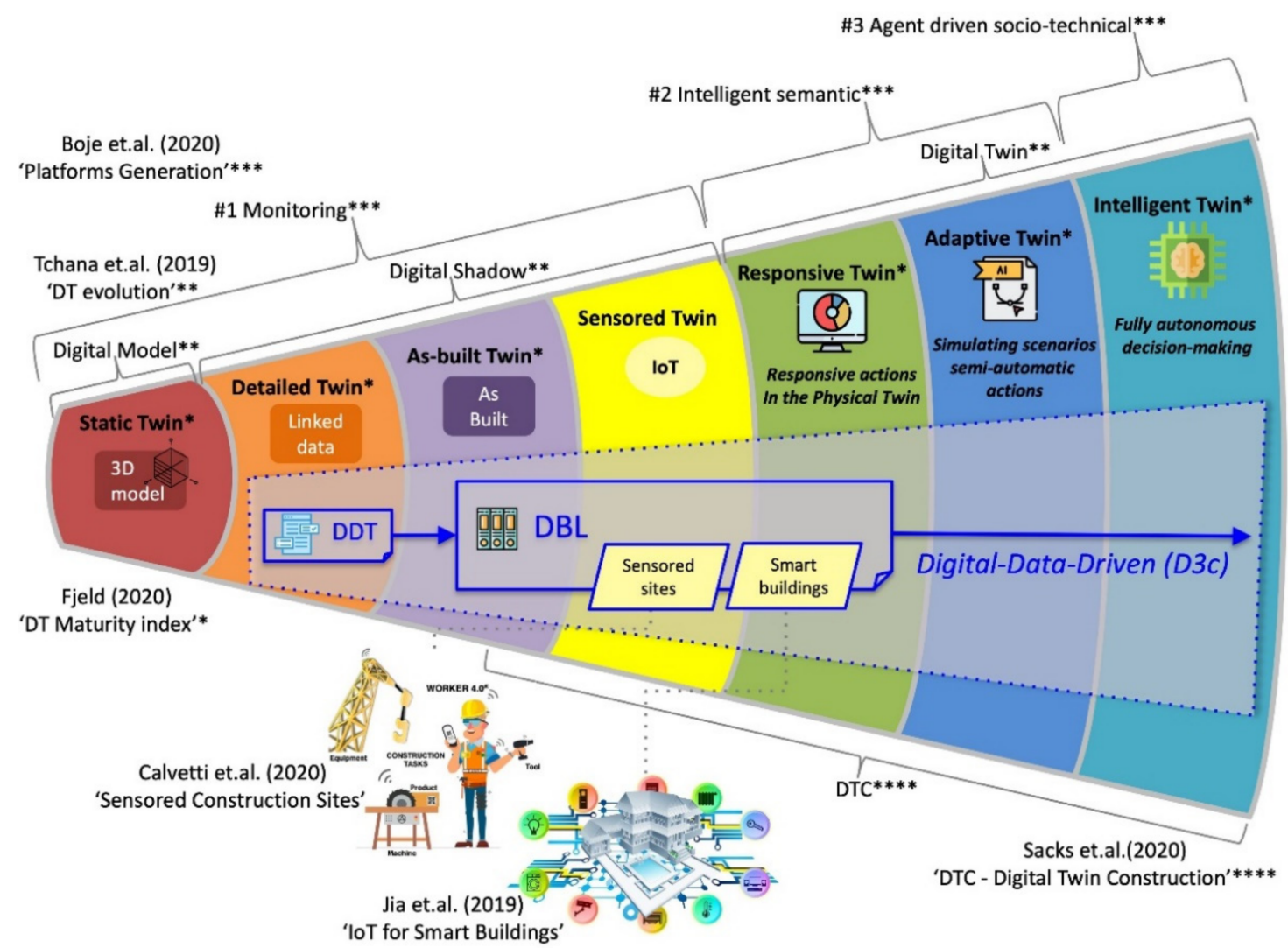

Figure 5. Digital twin construction incremental maturity levels (proposed conceptualisation V.1.0) The several $\left(^{*}\right)$ identify

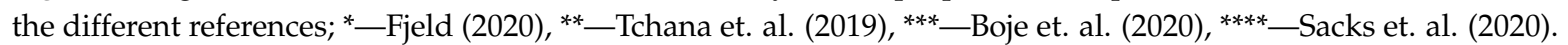


An evolutive twin mindset will allow the AECOO sector to conceptualise and implement digital twins interconnecting the project phases achieving more outcomes and increasing performance. Of course, the specific requirements of each project will drive the amount of "intelligence" of each DTC. However, an incremental and digital data-driven approach will always work in favour of projects' value.

Moreover, to obtain the full benefits and to use most of the advanced levels tools, it should be demanded to go back to the lowest level and implement some practices that, for example, will provide the background data in an appropriate format for a specific process in a following level. A moving up and down process to interconnect the levels might sometimes be necessary and beneficial. Those levels are not silos and if a level was achieved in a specific project this do not indicates that a stakeholder is in that level forever. As an example, it is possible to have an app in user's smartphone to command the turn on and turn out of the lights on a building entrance. Yes, it has a digital twin bidirectional interconnecting the physical and the virtual environment; however, strategic thinking should be made to realize if it is a complete experience in this field and if it is achieving the best performance that a smart building can have.

By analogy, the evolutive twin starts blind, deaf, and mute. It is a static twin in its first life stage. Through the adding and linking of data, preferable DDT, its eyes open. Still, this detailed twin maintains as deaf and mute. When the "as-built" twin starts hearing what happens in the construction phase, it is perceived as some evolution, hoping that to set it down in a digital way (DBL). However, it has no voice yet. Furthermore, after being powered by IoT, this sensored twin has no more disabilities, appearing with the ability to see, hear and talk. Still, its smartness depends on the humans behind it. To be human-independent, the twin should be "artificial intelligent". So, the twin powered by machine intelligence starts to take some own actions, being now a responsive twin. Over a process of learning and simulating many scenarios (more than a human can realise), the twin becomes mature and starts to be an adaptive twin. In the end, the twin is a fully responsible and autonomous one and has the ability to make its own decisions and runs the virtual and the physical environment as an intelligent twin.

\subsection{Incremental DTC Framework}

Finally, Figure 6 presents a prototype model to survey the construction companies to identify and diagnose their DTC maturity levels. It should be more than a "yes or no" questionnaire to allow a deep understanding of the maturity level. Because of that, some follow-ups questions are planned to provide more than a simple status, a diagnosis of that digital twin construction maturity. A deep diagnosis will avoid a misleading classification and indicates a path to grow. The outcome should indicate the actual level and what is needed to be done in the lowest levels to fulfil their requirements properly and upscaling that maturity levels targeting the most advanced DTC levels. In the near future, it is meant to survey the AECOO sector in order first to calibrate this DTC maturity level and to assess in detail the industry maturity. 


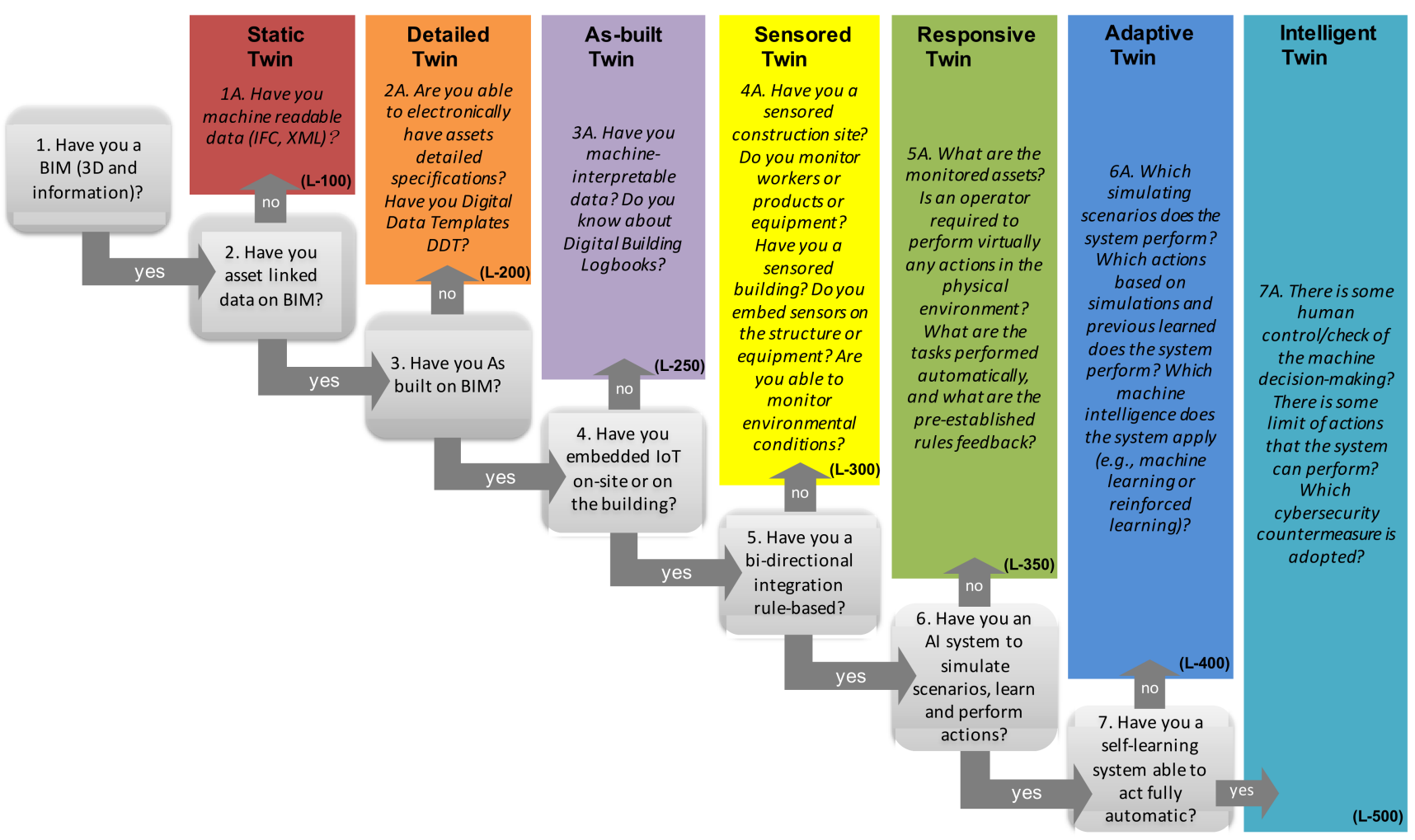

Figure 6. DTC incremental maturity levels diagnosis framework (V.1.0).

\section{Conclusions}

Digital twin construction (DTC) is a data-driven concept. This specific aspect is found to be key for the AECOO stakeholders to understand that digitalisation and sustainability goals rely on the good use and management of data. In addition, DTC is not a turnkey solution. It is an incremental process, built on other concepts and systems.

Despite previous studies pointing DT with several stages or maturities, an incremental vision for DTC benefiting from the positioning, objectives, and data contained in the DDT and DBL constitutes a novelty and one of the study contributions. Given the DDT ability to structure and capture construction objects characteristics in a machine-readable way and the DBL purpose of working as a framework for all relevant buildings' information storage, there are overlaps between these concepts in terms of the data used, captured, or managed.

In brief, this research evidences that digital data templates (DDT) and digital building logbooks (DBL) are critical elements for an improved growth of the DTC during the construction process life cycle, working as enablers and "sense" providers.

DDT and DBL gain traction during the design and construction phases, where the notion of DTC as a SoS can be used to support the multiple dimensions. Sensoring increases the amount of data collected and the ability to structure it in an efficient way is key. Sensored twin (Level 300) benefits from DBL as a major information container for relevant building information, understood as data related with the object to be built or in construction and all relevant information to be captured and collected during the construction process within a sensored construction site environment, supporting not just the products data management, but also the equipment and the craft workforce.

This phase is therefore key as demonstrates that based on IoT sensors and systems, a more autonomous bidirectional integration from the physical to the virtual environment becomes possible, setting the base for, during the use phase, materialize the smart building digital twin.

The traction gained by these solutions during the construction life cycle provides all the required information to better evaluate and analyse the reuse or recycling ability of elements and components. In these cases, the products characterisation for acceptance in the "new 
life" is already there, using digital and structured machine-readable data. If the destination is waste, the characterisation is in the same way there. As so, the presented solutions framed on the conceptualisations can be assumed as circular construction enablers.

The future of the construction industry relies on the best use of data. An incremental twin mindset will foster the implementation of digital twins interconnecting the project phases and achieving increased performance and outcomes. The ability to improve circularity in the construction industry relies on the capacity to capture built environment- or construction-related knowledge and the way to accomplish it is by perceiving and aligning digital data-driven concepts throughout the construction life cycle.

Our outcomes provide contribution bringing clarity for a better understanding of the concepts. Mainly, how they can work together as construction innovation enablers at digital and sustainability levels targeting circular practices engagement.

The developed research aims to add several contributions but also raised issues for future research works, as follows:

- The focus on the detailed identification of the data overlaps between the different concepts using case studies. Their aim is to validate and evolve on the DDT, DBL, and DTC enabling the digital data-driven concept (D3c), as presented in Figure 4.

- At DBL level, research on the data to collect and on the framework to structure, support, manage, capture, and exchange data following this vision will constitute also a field of action.

- The digital twin construction incremental maturity levels, presented in Figure 5, will be further explored and validated following multiple directions. One aims to validate the incremental DTC framework by developing focus group and survey, using the assumptions presented in the DTC incremental maturity levels diagnosis framework (Figure 6). The second aims to explore further the different environmental characteristics of the incremental DTC maturity levels presented. This will be accomplished by an already ongoing literature study following the work from Fjeld and Hjelseth [10] to better evaluate the levels referred to in different studies and in which degree there are examples of ideas, possible uses, or real cases. In addition, by working the data environments within a human-centric approach and the IoT, exploring for both the main barriers and challenges.

This study demonstrates that DDT, DBL, and DTC are related concepts that need to be further integrated. In this respect, the proposed digital data-driven concept (D3c) works as a foundation for integration. The proposed digital twin construction incremental maturity levels can act as a framework to bring awareness to stakeholders to increase projects' digital smartness. This digital data-driven approach conducts to a full deployment of the digital twins.

Author Contributions: Conceptualization, P.M. and D.C.; methodology, D.C. and P.M.; software, D.C.; validation, P.M., D.C., H.S. and E.H.; formal analysis, D.C., P.M., H.S. and E.H.; writingoriginal draft preparation, D.C., P.M., H.S. and E.H.; supervision, H.S. and E.H.; project administration, P.M. and E.H.; funding acquisition, P.M., H.S. and E.H. All authors have read and agreed to the published version of the manuscript.

Funding: This research was funded by the following: 1. European Economic Area (EEA) Financial Mechanism 2014-2021, Environment, Climate Change and Low Carbon Economy Programme: 13_Call\#2 GrowingCircle 2. Base Funding of the CONSTRUCT - Instituto de I\&D em Estruturas e Construções-funded by national funds through the FCT/MCTES (PIDDAC): UIDB/04708/2020.

Informed Consent Statement: Not applicable.

Conflicts of Interest: The authors declare no conflict of interest. 


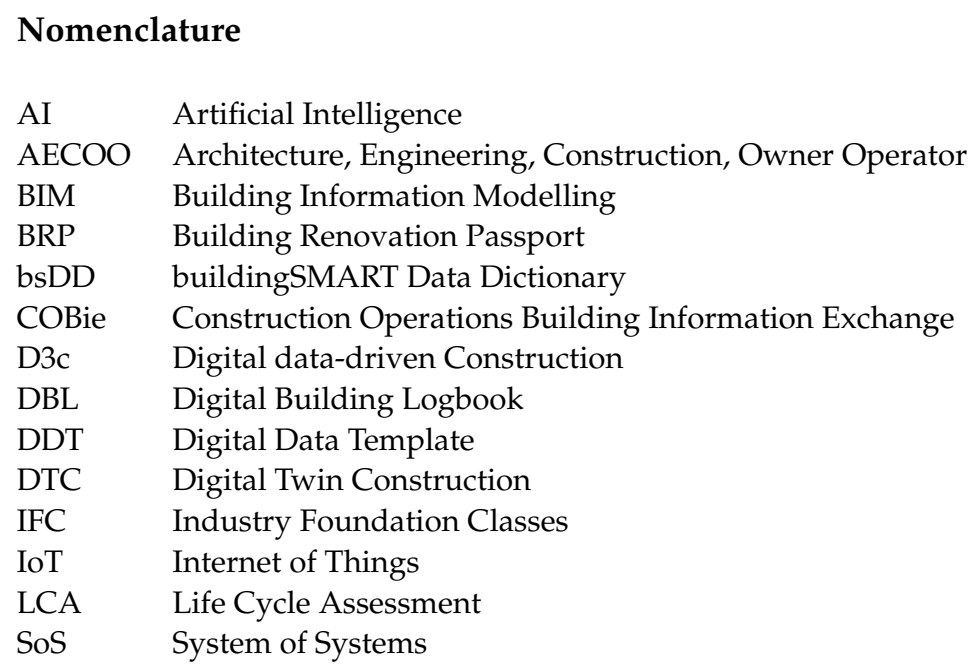

\section{References}

1. European Commission. The European Green Deal; European Commission: Brussels, Belgium, 2019; Volume 53, p. 24. [CrossRef]

2. European Commission. A Monitoring Framework for the Circular Economy COM(2018) 29 Final. COM/2018/29 Final; European Commission: Strasbourg, France, 2018; Volume 29, pp. 1-11.

3. European Union. A Renovation Wave for Europe-Greening Our Buildings, Creating Jobs, Improving Lives. COM(2020); European Commission: Brussels, Belgium, 2020; pp. 1-26.

4. European Commission. Guidelines for the Waste Audits before Demolition and Renovation Works of Buildings. UE Construction and Demolition Waste Management; Ref. Ares(2018)4724185-14/09/2018; European Commission: Brussels, Belgium, 2018 ; p. 37.

5. BuildingSMART. Enabling an Ecosystem of Digital Twins. 2020. Available online: https://www.buildingsmart.org/ buildingsmart-positioning-paper-enabling-an-ecosystem-of-digital-twins / (accessed on 12 May 2021).

6. European Construction Sector Observatory. Digitalisation in the Construction Industry; European Commission: Brussels, Belgium, 2021.

7. Boje, C.; Guerriero, A.; Kubicki, S.; Rezgui, Y. Towards a semantic Construction Digital Twin: Directions for future research Autom. Constr. 2020, 114, 103179. [CrossRef]

8. Sacks, R.; Brilakis, I.; Pikas, E.; Xie, H.S.; Girolami, M. Construction with digital twin information systems. Data-Cent. Eng. 2020, 1. [CrossRef]

9. Tchana, Y.; Ducellier, G.; Remy, S. Designing a unique Digital Twin for linear infrastructures lifecycle management. Procedia CIRP 2019, 84, 545-549. [CrossRef]

10. Fjeld, T.M.B. Digital Twin-Towards a joint understanding within the AEC/FM sector. Master's Thesis, Norwegian University of Science and Technology, Trondheim, Norway, 2020.

11. Calvetti, D.; Mêda, P.; Gonçalves, M.C.; Sousa, H. Worker 4.0: The Future of Sensored Construction Sites. Buildings 2020, 10, 169. [CrossRef]

12. Jia, M.; Komeily, A.; Wang, Y.; Srinivasan, R.S. Adopting Internet of Things for the development of smart buildings: A review of enabling technologies and applications. Autom. Constr. 2019, 101, 111-126. [CrossRef]

13. ISO/FDIS 23387:2020(E). Building Information Modelling (BIM)—Data Templates for Construction Objects Used in the Life Cycle of Any Built Asset-Concepts and Principles; ISO: Vernier, Switzerland, 2020.

14. European Commission. Study on the Development of a European Union Framework for Digital Building Logbooks; Final Report; European Commission: Brussels, Belgium, 2020.

15. Mêda, P.; Hjelseth, E.; Calvetti, D.; Sousa, H. Enabling circular construction information flows using Data Templates-Conceptual approach for Waste Audit. In Proceedings of the The 2021 European Conference on Computing in Construction (2021 EC3), Rhodes, Greece, 19-28 July 2021.

16. Cecconi, F.R.; Dejaco, M.C.; Maltese, S. Efficiency indexes for building condition assessment. Int. J. Hous. Sci. Its Appl. 2014, 38, 271-279.

17. Gigante-Barrera, Á.; Ruikar, D.; Crunden, M.; Ruikar, K. Lod object content specification for manufacturers within the UK using the idm standard. J. Inf. Technol. Constr. 2017, 22, 80-103.

18. Pritchard, R.; Kelly, S. Realising operational energy performance in non-domestic buildings: Lessons learnt from initiatives applied in Cambridge. Sustainability 2017, 9, 1345. [CrossRef]

19. Sousa, H.; Mêda, P.; Moreira, J.; Costa, R. Construction products information Importance and influence towards digitalization. Rehabend 2018, 1665-1673.

20. Park, S.; Park, S.H.; Park, L.W.; Park, S.; Lee, S.; Lee, T.; Lee, S.H.; Jang, H.; Kim, S.M.; Chang, H.; et al. Design and implementation of a Smart IoT based building and town disaster management system in Smart City Infrastructure. Appl. Sci. 2018, 8, 2239. [CrossRef] 
21. Sesana, M.M.; Salvalai, G. A review on Building Renovation Passport: Potentialities and barriers on current initiatives. Energy Build. 2018, 173, 195-205. [CrossRef]

22. Borth, M.; Verriet, J.; Muller, G. Digital twin strategies for SoS: 4 challenges and 4 architecture setups for digital twins of SoS. In Proceedings of the 2019 14th Annual Conference System of Systems Engineering (SoSE), Anchorage, AK, USA, 19-22 May 2019; pp. 164-169. Available online: https:/ / ieeexplore-ieee-org.ukzn.idm.oclc.org/stamp/stamp.jsp?tp=\&arnumber=8753860 (accessed on 10 May 2021).

23. Ganter, M.; Lützkendorf, T. Information management throughout the life cycle of buildings-Basics and new approaches such as blockchain. In Proceedings of the Sustainable Built Environment D-A-CH Conference 2019 (SBE19 Graz), Graz, Austria, 11-14 September 2019; Volume 323. [CrossRef]

24. Lucky, M.N.; Pasini, D.; Spagnolo, S.L. Product Data Management for Sustainability: An Interoperable Approach for Sharing Product Data in a BIM Environment. In Proceedings of the SBE19-Resilient Built Environment for Sustainable Mediterranean Countries, Milan, Italy, 4-5 September 2019. [CrossRef]

25. Zirngibl, J.; Mateo-Cecilia, C.; Espigares-Correa, C. Alliance for deep renovation in buildings. A step forward to the common European voluntary certification scheme. E3S Web Conf. 2019, 111, 03005. [CrossRef]

26. Signorini, M.; Frigeni, S.; Spagnolo, S.L. Integrating environmental sustainability indicators in BIM-based product datasheets. In Proceedings of the SBE19-Resilient Built Environment for Sustainable Mediterranean Countries, Milan, Italy, 4-5 September 2019. [CrossRef]

27. Chevallier, Z.; Finance, B.; Boulakia, B.C. A reference architecture for smart building digital twin. In SeDiT 2020 Semantic Digital Twins 2020; Garcia-Castro, A.G.F.C., Davies, J.R., Antoniou, G., Fortuna, C., Eds.; SeDit: Heraklion, Greece, 2020.

28. FGray, M.; Dibowski, H.; Gall, J.; Braun, S. Occupant Feedback and Context Awareness: On the Application of Building Information Modeling and Semantic Technologies for Improved Complaint Management in Commercial Buildings. In Proceedings of the 2020 25th IEEE International Conference on Emerging Technologies and Factory Automation (ETFA), Vienna, Austria, 8-11 September 2020; pp. 101-108. [CrossRef]

29. Spagnolo, S.L.; Amosso, G.; Pavan, A.; Daniotti, B. BIMReL: The interoperable bim library for construction products data sharing. In Digital Transformation of the Design, Construction and Management Processes of the Built Environment; Research for Development; Springer: Cham, Switzerland, 2020; pp. 37-47. [CrossRef]

30. Kuller, M.; Kohlmorgen, F.; Karaoglan, N.; Niemeyer, M.; Kunold, I.; Wohrle, H. Conceptual design of a digital twin based on semantic web technologies in the smart home context. In Proceedings of the 2020 IEEE 3rd International Conference and Workshop in Obuda on Electrical and Power Engineering, Budapest, Hungary, 18-19 November 2020; pp. 167-172. [CrossRef]

31. Gelder, J. Uniclass 2015 for smart cities. In Proceedings of the International Conference of Architectural Science Association, Auckland, New Zealand, 25-28 November 2020; Architectural Science Association: Auckland, New Zealand, 2020; pp. 1303-1312.

32. Al-Ali, A.R.; Gupta, R.; Batool, T.Z.; Landolsi, T.; Aloul, F.; Al Nabulsi, A. Digital twin conceptual model within the context of internet of things. Future Internet 2020, 12, 163. [CrossRef]

33. Liu, Z.; Zhang, A.; Wang, W. A framework for an indoor safety management system based on digital twin. Sensors 2020, $20,5771$. [CrossRef] [PubMed]

34. Sai, Y.; Zhang, T.; Huang, X.; Ding, C. Analysis of digital twins and application value of power engineering based on BIM. In International Conference on Big Data Analytics for Cyber-Physical-Systems; Springer Nature Singapore Pte Ltd.: Singapore, 2020; pp. 550-558. [CrossRef]

35. Deng, M.; Menassa, C.C.; Kamat, V.R. From BIM to digital twins: A systematic review of the evolution of intelligent building representations in the AEC-FM industry. J. Inf. Technol. Constr. 2021, 26, 58-83. [CrossRef]

36. Barontini, A.; Alarcon, C.; Sousa, H.S.; Oliveira, D.V.; Masciotta, M.G.; Azenha, M. Development and Demonstration of an HBIM Framework for the Preventive Conservation of Cultural Heritage. Int. J. Archit. Herit. 2021, 1-23. [CrossRef]

37. Sesana, M.M.; Salvalai, G.; Brutti, D.; Mandin, C.; Wei, W. ALDREN: A methodological framework to support decision-making and investments in deep energy renovation of non-residential buildings. Buildings 2021, 11, 3. [CrossRef]

38. Edirisinghe, R. Digital skin of the construction site: Smart sensor technologies towards the future smart construction site. Eng. Constr. Archit. Manag. 2019, 26, 184-223. [CrossRef]

39. Watson, R.; Kassem, M.; Li, J. Traceability for Built Assets: Proposed Framework for a Digital Record. In Proceedings of the Creative Construction Conference (2019) 068, Budapest, Hungary, 29 June-2 July 2019; pp. 496-501. [CrossRef]

40. Succar, B.; Poirier, E. Lifecycle information transformation and exchange for delivering and managing digital and physical assets. Autom. Constr. 2020, 112, 103090. [CrossRef]

41. Mêda, P.; Sousa, H.; Hjelseth, E. Data Templates-Traceability and Digital Record Through Project Life-Cycle. J. Appl. Bus. Econ. 2020, 22, 274-291. [CrossRef]

42. Tagliabue, L.C.; Cecconi, F.R.; Maltese, S.; Rinaldi, S.; Ciribini, A.L.C.; Flammini, A. Leveraging digital twin for sustainability assessment of an educational building. Sustainability 2021, 13, 480. [CrossRef]

43. Yitmen, I.; Alizadehsalehi, S.; Akıner, I.; Akıner, M.E. An Adapted Model of Cognitive Digital Twins for Building Lifecycle Management. Appl. Sci. 2021, 11, 4276. [CrossRef]

44. HM Government. Digital Built Britain Level 3 Building Information Modelling-Strategic Plan; UK Government: London, UK, 2015.

45. Fabbri, M.; de Groote, M.; Rapf, O. Building Renovation Passports: Customised Roadmaps towards Deep Renovation and Better Homes; Buildings Performance Institute Europe (BPIE): Brussels, Belgium, 2016. 
46. Thompson, S. Product Data Definition: A Technical Specification for Defining and Sharing Structured Digital Construction Product Information; BIM Task Group: London, UK, 2016.

47. Product Data Working Group. A Fresh Way Forward For Product Data; UK BIM Alliance: London, UK, 2018.

48. BS EN ISO 19650-1:2018. Organization and Digitization of Information about Buildings and Civil Engineering Works, Including Building Information Modelling (BIM)_Information Management Using Building Information Modelling; CEN-CENELEC Management Centre: Brussels, Belgium, 2018.

49. BS EN ISO 19650-2:2018. Organization and Digitization of Information about Buildings and Civil Engineering Works, Including Building Information Modelling (BIM)_Information Management Using Building Information Modelling; CEN-CENELEC Management Centre: Brussels, Belgium, 2018.

50. Brilakis, I.; Pan, Y.; Borrmann, A.; Mayer, H.-G.; Rhein, F.; Vos, C.; Pettinato, E.; Wagner, S. Built Environment Digital Twinning; Report of the International Workshop on Built Environment Digital Twinning presented by TUM Institute for Avanced Study and Siemens AG; Technical University of Munich: Munich, Germany, 2019.

51. Neely, A.; Schooling, J.; Boulton, C.; Lamb, K. Developing the Capabilities for a Digital Built Britain; Centre for Digital Built Britain: Cambridge, UK, 2019. [CrossRef]

52. Daskalova, M.; Dermenjiev, S.; Blonk, E.; Mercer, A.; Schulze, E.; Surin, P. Digital Supply Chains: Data Driven Collaboration; Digital Supply Chains in the Built Environment-(DSCiBE) User Group: Berm, Switzerland, 2019.

53. Mario, G.; Crean, G.; Boever, E. The Data-Driven Innovation Strategy for the Development of a Trusted and Sustainable Economy in Luxembourg; Ministry of the Economy: Luxembourg, 2019.

54. BS EN 17412-1:2020. BSI Standards Publication Building Information Modelling—Level of Information Need; CEN-CENELEC Management Centre: Brussels, Belgium, 2020.

55. PAS 14191:2020. Built Environment-Management and Operation of Interconnected Construction Data Dictionaries-Specification; BSI Standards Limited: London, UK, 2020.

56. Gilbert, T.; Gruler, H.-C.; Kolbe, T.H.; Mercer, A.; Nisbet, N.; Plume, J.; Rönsdorf, C.; Simmons, S.; van Berlo, L. Built Environment Data Standards and Their Integration: An Analysis of IFC, City GML and LandInfra; Open Geospatial Consortium \& buildingSMART International: Arlington, TX, USA, 2020.

57. Allison, N.; Hartley, G. Digital Product Data for Lifting Productivity; BRANZ Inc.: Wellington, New Zealand, 2020.

58. East, E.W.; Ford, J. Lean Handover: COBie for Contractors; Prairie Sky Consulting LLC: Mahomet, IL, USA, 2019.

59. Verbeke, S.; Aerts, D.; Reynders, G.; Ma, Y.; Waide, P. Final Report on the Technical Support to the Development of a smart Readiness Indicator for Buildings; European Commission: Brussels, Belgium, 2020.

60. Božiček, D.; Kunič, R.; Košir, M. Interpreting environmental impacts in building design: Application of a comparative assertion method in the context of the EPD scheme for building products. J. Clean. Prod. 2021, 279, 123399. [CrossRef]

61. Rangelov, M.; Dylla, H.; Mukherjee, A.; Sivaneswaran, N. Use of environmental product declarations (EPDs) of pavement materials in the United States of America (U.S.A.) to ensure environmental impact reductions. J. Clean. Prod. 2021, $283,124619$. [CrossRef]

62. Durão, V.; Silvestre, J.D.; Mateus, R.; de Brito, J. Assessment and communication of the environmental performance of construction products in Europe: Comparison between PEF and EN 15804 compliant EPD schemes. Resour. Conserv. Recycl. 2020, 156, 104703. [CrossRef]

63. Sariola, L.; Ilomaki, A. RTS EPD's-Different Methods of Producing Reliable Environmental Information of Building Products in Finland. In Proceedings of the SBE 19-Emerging Concepts for Sustainable Built Environment, Helsinki, Finland, 22-24 May 2019; Volume 297. [CrossRef]

64. Biswas, W.K.; Alhorr, Y.; Lawania, K.K.; Sarker, P.K.; Elsarrag, E. Life cycle assessment for environmental product declaration of concrete in the Gulf States. Sustain. Cities Soc. 2017, 35, 36-46. [CrossRef]

65. Rochikashvili, M.; Bongaerts, J.C. How eco-labelling influences environmentally conscious consumption of construction products. Sustainability 2018, 10, 351. [CrossRef]

66. Gelowitz, M.D.C.; McArthur, J.J. Comparison of type III environmental product declarations for construction products: Material sourcing and harmonization evaluation. J. Clean. Prod. 2017, 157, 125-133. [CrossRef]

67. Lützkendorf, T.P. Product data and building assessment-Flow of information. In Proceedings of the SBE19 Brussels-BAMBCIRCPATH "Buildings as Material Banks-A Pathway For A Circular Future", Brussels, Belgium, 5-7 February 2019 ; Volume 225. [CrossRef]

68. Lasvaux, S.; Schiopu, N.; Habert, G.; Chevalier, J.; Peuportier, B. Influence of simplification of life cycle inventories on the accuracy of impact assessment: Application to construction products. J. Clean. Prod. 2014, 79, 142-151. [CrossRef]

69. Lasvaux, S.; Habert, G.; Peuportier, B.; Chevalier, J. Comparison of generic and product-specific Life Cycle Assessment databases: Application to construction materials used in building LCA studies. Int. J. Life Cycle Assess. 2015, 20, 1473-1490. [CrossRef]

70. BuildingSMART. buildingSMART Data Dictionary-buildingSMART International. (n.d.). Available online: https://www. buildingsmart.org/users/services/buildingsmart-data-dictionary/ (accessed on 15 June 2021).

71. JRC. Summary Report on Status of implementation of the INSPIRE Directive in EU. EUR 2017, 28930, 20. [CrossRef]

72. Grieves, M.W. BDTIC 2021—BDTA; Building Digital Twin International Congress-BDTIC: Antwerpen, Belgium, 2021. 
73. Calvetti, D.; Mêda, P.; Sousa, H.; Gonçalves, M.C. Human Data Interaction in Sensored Sites, Challenges of the Craft Workforce Dimension. In Proceedings of the The 2021 European Conference on Computing in Construction (2021 EC3), Rhodes, Greece, 26-28 July 2021.

74. Calvetti, D.; Magalhães, P.N.M.; Gonçalves, M.C.; de Sousa, H.J.C.; Magalhães, P.N.M.; de Sousa, H.J.C. Sensing technologies embedding construction workers outcomes/key performance indicators. In Proceedings of the 36th CIB W78 2019 Conference: Advances in ICT in Design, Construction and Management in Architecture, Engineering, Construction and Operations (AECO), Newcastle, UK, 18-20 September 2019; pp. 890-900.

75. PMI. A Guide to the Project Management Body of Knowledge (PMBOK Guide), 6th ed.; Project management Institute: Newtown Square, PA, USA, 2017.

76. IEA International Energy Agency. IEA EBC ANNEX 57-Overview of Annex 57 Results; Institute for Building Environment and Energy Conservation: Tokyo, Japan, 2016.

77. Calvetti, D.; Gonçalves, M.; Vahl, F.; Mêda, P.; de Sousa, H. Labour Productivity as a means for Assessing Environmental Impact in the Construction Industry. Environ. Eng. Manag. J. 2021, 20, 781-790. 